\title{
EXPERIMENTAL STUDY OF THE HEALING \\ OF FRACTURES *
}

LEONARD W. ELY, M.D.

SAN FRANCISCO

This study was undertaken to clear up several obscure points in the process of healing of fractures, but chiefly to ascertain the exact rôle assumed by the periosteum. Three sets of experiments were performed on cats, and in all the humerus was fractured.

In the first series, the humerus was fractured by direct external violence, applied laterally. I used my thumb as a fucrum, and, in case the bone was too tough to be broken thus, I broke it over the edge of the table. In the second series, I made a lateral incision, dissected the tissues down to the periosteum, divided the periosteum circularly, fractured the bone with a Gigli saw or Liston bone forceps, and sutured the wound. The third series was similar to the second, except that the periosteum was simply slit longitudinally to give access to the bone.

Complete narcosis under ether was employed, and in the open operations due attention was given to asepsis. The cats were killed at intervals, Cats 16 and 17 with chloroform, the rest with illuminating gas.

The fractured bone, with its periosteum, was removed shortly after death, and was fixed in from 4 to 10 per cent. liquor formaldehydi, and was decalcified in a 5 per cent. solution of nitric acid. In the case of three cats (Cats 10,11 and 12), the bones were placed immediately in nitric acid solution by mistake, without previous fixation. All but these three were roentgenographed before decalcification. Each specimen was divided longitudinally, was run up through the alcohols and ether, and was mounted in celloidin. Sections were cut and stained with hematoxylin and eosin, and with the Unna and van Gieson stains.

PROTCCOL OF EXPERIMENTS

FIRST SERIES: SIMPLE FRACTCRE BY DIRECT VIOI.ENCE

EXPERIMENT 1.-Cat 1, a large sized, adult animal, was killed with illuminating gas, four days after the fracture. Marked ecchymosis was revealed when the cat was skinned. There was marked displacement of the fragments, with overriding. The bone was removed, together with the surrounding tissues, and was sectioned longitudinally. One half the specimen was decalcified, embedded, cut and stained.

The stained slide showed no overriding, but slight lateral displacement. The bones were situated end to end. The marrow canal of one was open, but the knife had caught the other bone obliquely so that its cortex shut off its canal on

* From the laboratory of surgical pathology, Stanford University. 
the slide. In the tissues about the ends of both bones was much fibrin, and a mass of fibrin in which were one or two bone spicules separated the two. The surrounding tissues showed cellular infiltration.

Fragment with the Open Canal.-The lymphoid marrow appeared as a band on each side of the canal, plugging up the end, with the fatty marrow in the center. A layer of fibrin also lay partly across the end of the canal. The periosteum showed two distinct layers of about equal thickness, an inner, or cellular, and an outer, or fibrous layer. It ended a short distance from the fractured extremity, leaving the cortex bare. The outside of the cortex on one side was irregular and notched, and showed an irregularity of staining reaction, as if it were already being attacked, and it looked as if the formation of Howship's lacunae were beginning, but no giant cell osteoclasts were in evidence. This observation, if correctly made, would indicate that the so-called osteoclasts were not the cause of the osteoclasis, but the result.

Fragment with the Closed End.-This contained lymphoid marrow. The cortex was covered with periosteum in two distinct layers, the inner increasing markedly in thickness toward the end of the bone. The marrow canal contained many bone trabeculae.

Summary.-The ends of the fragments were buried in fibrin. There was an aggregation of lymphoid marrow at the circumference of the marrow canal of one fragment. The periosteum lay in two distinct layers.

Experiment 2.-Cat 2, a full grown cat, was killed with illuminating gas, eight days after the fracture. There was no sign of epiphyseal cartilage in the head of the humerus. Less ecchymosis was present than in the first cat, and that only about the elbow and fore leg. There was much overriding of the fragments. The bone was removed with the surrounding tissue.

Two sets of slides were made. Each set showed one bone cut longitudinally, with its marrow canal open on the end, and the other cut diagonally, with its marrow canal closed by bone. Evidently, each fragment was cut fairly in one set of slides. One of the fragments showed splintering. The two fragments overlapped. Remains of hemorrhage were present at their ends. The ends were surrounded by granulation tissue, and this granulation tissue ran for a very short distance into the marrow canal as if to plug it up. The tips of the cortex showed well marked so-called rarefying osteitis.

The behavior of the periosteum was peculiar. At some distance from the fracture, it left the bone, the space between the two gradually widening, and showing distinct evidence of new bone trabeculae. The periosteum of one of the fragments was notable because of the presence in it, or in its immediate vicinity, of well marked hemorrhage. This line of hemorrhage made the course of the periosteum more distinct. It was not diffuse, but followed the periosteum closely. At a short distance from the broken end, the fibers of the periosteum diverged from one another, and, just before the end of the bone was reached, they were lost in the granulation tissue. No bone trabeculae appeared within the cortex.

The foregoing holds good for one fragment-the clean cut one. The splintered fragment showed a rather different picture. The periosteum was not so easily recognized, and no bone trabeculae appeared under it, except at some distance from the end. New bone trabeculae were abundant on the inside of the cortex.

Summary.-Granulation tissue surrounded the bone ends. There was beginning bone formation on the outside of the cortex of one fragment and on the inside of the cortex of the other. 


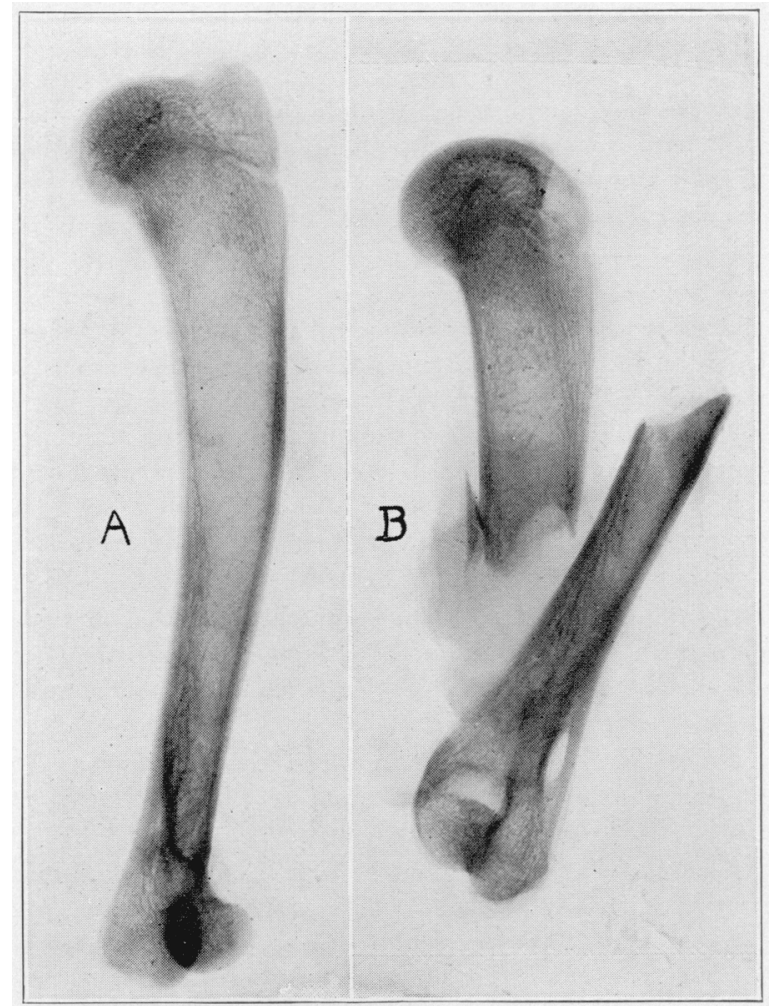

Fig. 1.- $A$, normal humerus of Cat $1 ; B$, fractured humerus of Cat 1 after removal.

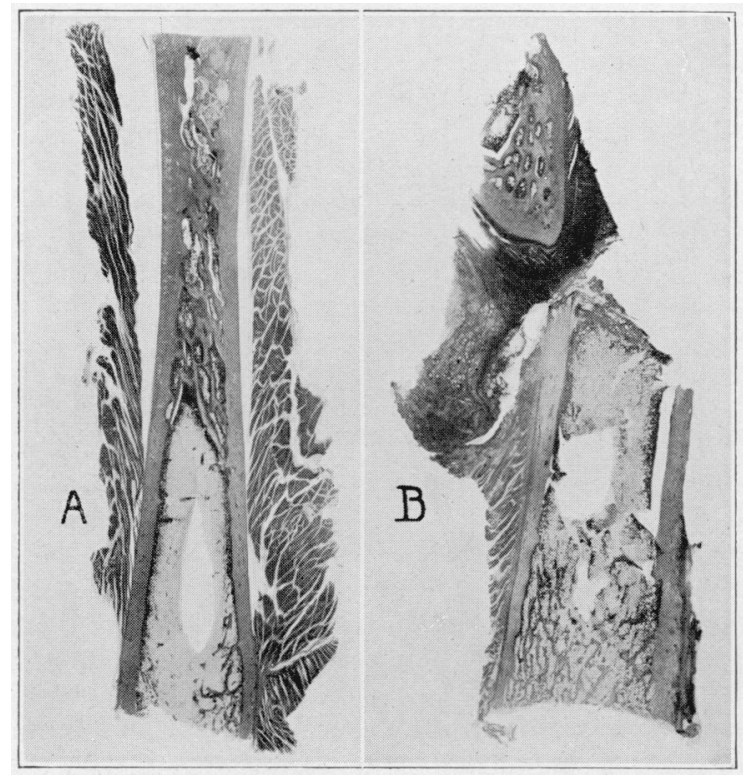

Fïg. 2.- $A$, stained slicle cut from normal humerus of Cat $1 ; B$, stained slide cut from fractured humerus of Cat 1. 
Experiment 3.-Cat 3 was killed with illuminating gas, thirteen days after the fracture. There was no ecchymosis. Thickening was present about the seat of fracture, but apparently there was less overriding than in Cats 1 and 2 . There was free motion. The bone was removed with the surrounding tissue, and sectioned longitudinally.

One of the bones had been caught by the knife in such a way that it appeared as a small point of bone slightly overlapping the irregular fractured end of the other fragment. The two fragments were bound together by a mass of fibrous tissue and cartilage; and in this fibrous and cartilaginous tissue, the formation of bone trabeculae was well advanced. Small spicules of bone, evidently fractured at the time of operation, could be seen here and there. The new trabeculae were especially abundant on the outside of the cortex, immediately beneath the periosteum. They capped the pointed fragment,

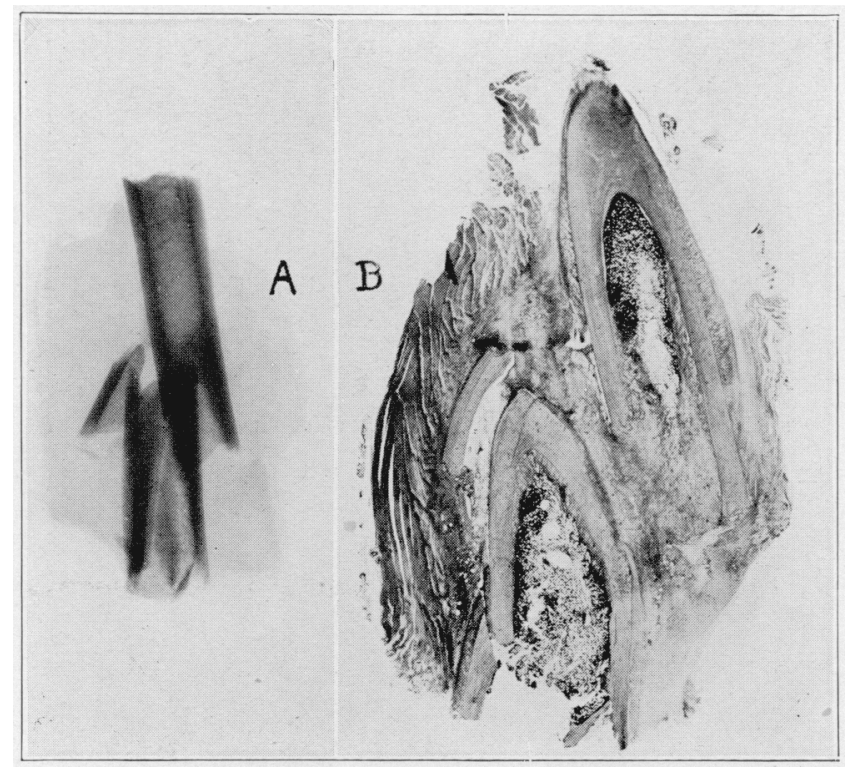

Fig. 3.- $A$, fractured humerus of Cat $2 ; B$, stained slide cut from fractured humerus of Cat 2.

and, on the other fragment, they were especially numerous on the far side of the cortex. In the latter fragment the formation of internal callus was beginning, not on the inner aspect of the cortex but in the marrow canal itself. One small fractured spicule of bone showed the formation of new trabeculae on its borders.

Summary.-The fragments were bound together by fibrous and fibrocartilaginous tissue, in which new bone was forming. New trabeculae were especially numerous on the outside of the cortex. There was some new bone formation within the canal of one fragment-so-called internal callus.

EXPERIMENT 4.-Cat 4 was killed with illuminating gas, sixteen days after fracture. There were slight remains of ecchymosis, thickening about the seat of fracture and marked overriding. The bone was removed with the surrounding tissue, and sectioned longitudinally. 


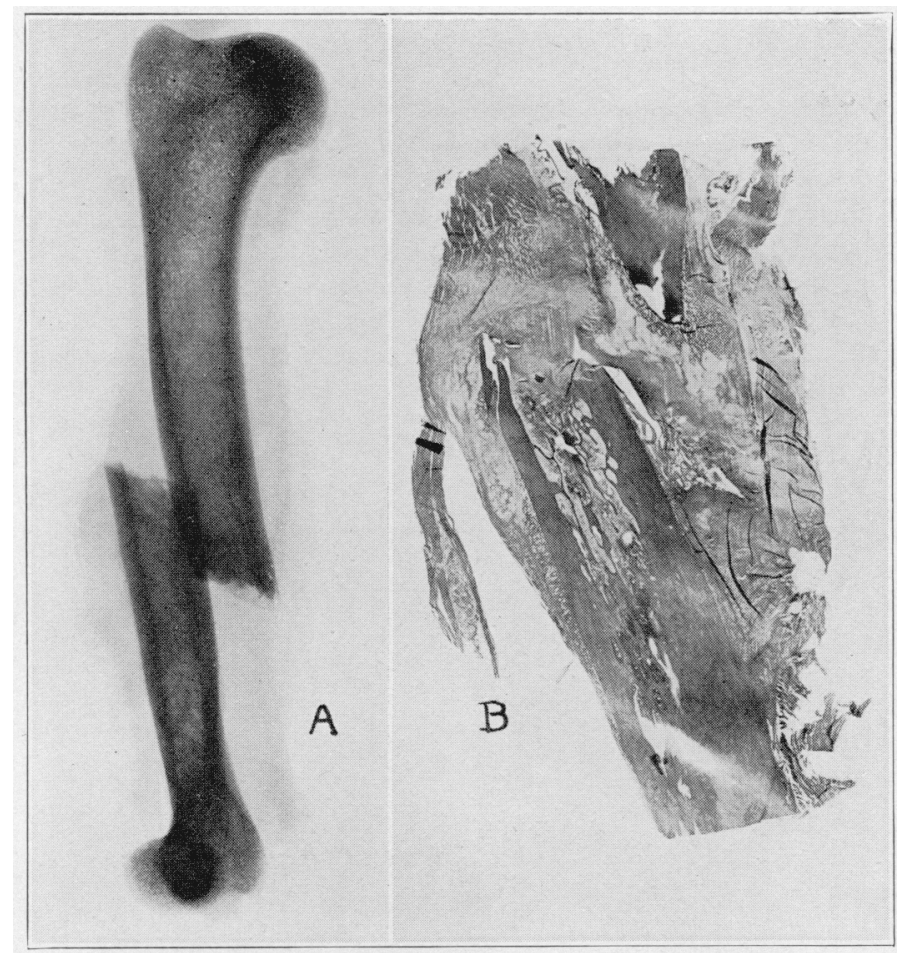

Fig. 4.- $A$, fractured humerus of Cat $3 ; B$, stained slide cut from fractured humerus of Cat 3 .

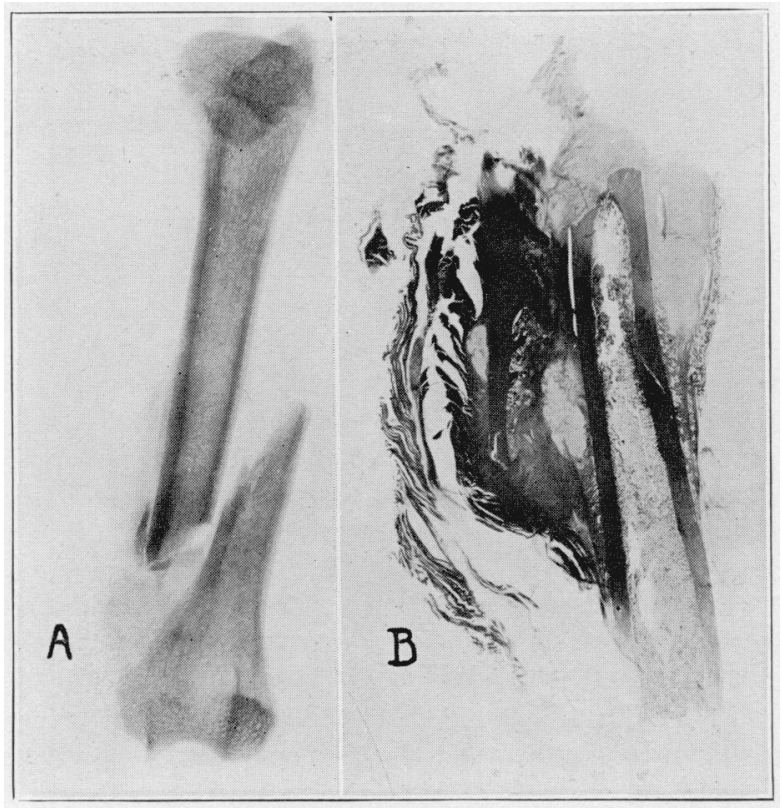

Fig. 5.- $A$, fractured humerus of Cat $4 ; B$, stained slide cut from fractured humerus of Cat 4. 
Examination of Staincd Slide.-The knife had caught one fragment fairly, but the other fragment evidently was split. The two fragments had overriden about $1.5 \mathrm{~cm}$. Dense bone almost shut off the marrow canal of the fragment caught fairly. This was evidently due to diagonal sectioning, because it was not new bone. At the end of each fragment was a mass of fibrous tissue containing rifts. Almost capping one fragment and extending well over on its far cortex was a large mass of cartilage. A much smaller area appeared on its near cortex, about a centimeter from its fractured end, and a still smaller piece on the outside of the far cortex of the other fragment, about $0.5 \mathrm{~cm}$. from its fractured end. Cartilage and fibrous tissue thus united the two fragments fairly firmly.

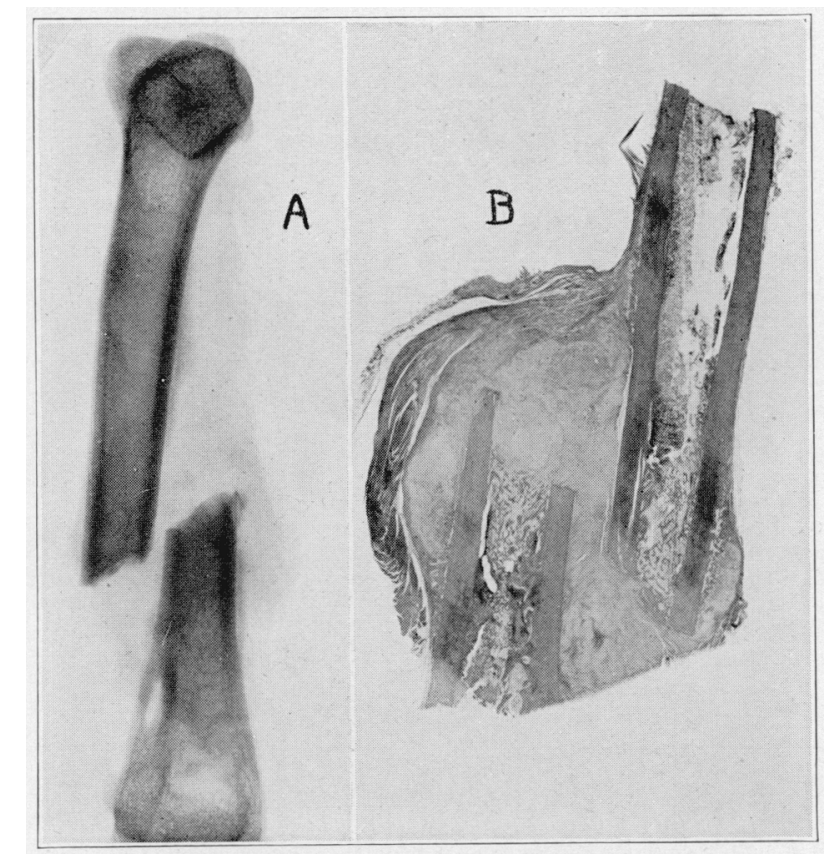

Fig. 6.- $A$, fractured humerus of Cat $5 ; B$, stained slide cut from fractured humerus of Cat 5 .

New bone trabeculae were forming on the outside of the cortex of both fragments, springing from it, as it were, not only in the masses of cartilage but also in and under the periosteum. Bone trabeculae were also forming on the inside of the cortex-internal callus.

Summary.-The fractured bones were united by cartilage and fibrous tissue, in which new bone trabeculae were forming. There were indications of internal callus in the marrow canals of both fragments, but this internal callus apparently played no effective part in the union.

EXPERIMENT 5.-Cat 5 was killed with illuminating gas, twenty days after fracture. There was considerable thickening at the seat of fracture with a little motion.

Examination of the Stained Slide.--The two fragments, overlapping about 6 or $8 \mathrm{~mm}$. and separated by an interval of abont $3 \mathrm{~mm}$, were bound together 
by a fusiform mass of fibrous tissue containing large and small islands of cartilage. Close to the bone cortex in places, ossification was beginning in this mass of new tissue, only to a minimal extent on one of the two apposed cortices, but to a much greater extent on the outside of the far cortex of each fragment. In the latter situation, intracartilaginous bone formation between the cortex and the periosteum was active and well advanced. New bone trabeculae were abundant in the marrow canal of each fragment in the neighborhood of its fractured extremity-the so-called internal callus. Continuous with the end of one cortex only new bone was being built up, apparently out of the fibrous tissue which embedded the end of the fragment. There were small rifts in the welding fibrous tissue.

Summary--The overlapping bones ended in a mass of fibrous tissue and cartilage, which surrounded them like a plumber's wiped joint. New bone was

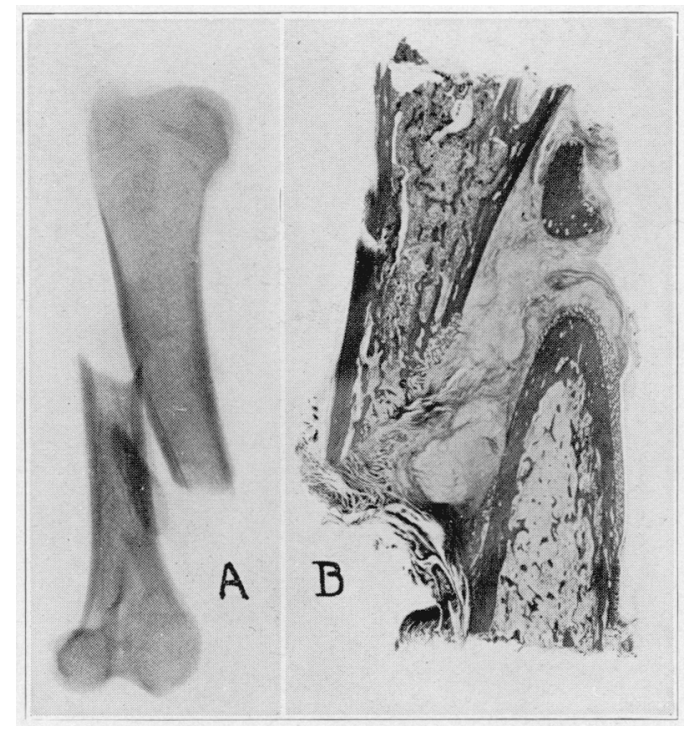

Fig. 7.- $A$, fractured humerus of Cat $6 ; B$, stained slide cut from fractured humerus of Cat 6 .

being built up in this fibrous tissue and cartilage. Internal callus was present in each marrow canal, but seemed to play no essential part in the process of healing.

Experiment 6.-Cat 6, a small, apparently young cat, was killed with illuminating gas, twenty-four days after fracture. The fragments showed marked overriding, and had no stability.

Examination of the Stained Slide.-The fragments overrode about $1 \mathrm{~cm}$. The end of one fragment was open; the end of the other was closed off by bone, evidently the bone of the old cortex caught by the knife at an oblique angle. Between the two fragments lay a mass of cartilage, fibrocartilage and fibrous tissue. Fibrous tissue lay over the open end of one fragment, a cap of cartilage over the closed end of the other. In these two situations, new bone formation was beginning. It was also beginning in the cartilage in the angle where the periosteum left the cortex of one fragment to pass across to that 
of the other, and externally on the cortex on the far side of one fragment. No indication of internal callus was present. A small fragment of bone lay at a short distance from the end of the closed fragment. It was probably part of a splinter. On it new bone was being formed. A large cleft or series of clefts ran from the end of one fragment, part way over to the other fragment in the fibrous tissue between the two bones.

Summary.-The bones were united by fibrous tissue containing masses of cartilage, especially in the immediate vicinity of the cortices. The marked instability, together with the presence of the rifts in the fibrous tissue, indicated that perhaps a false joint was in process of formation.

EXPERIMENT 7.-Cat 7, a small, probably young animal, was killed with illuminating gas, twenty-eight days after the fracture. There were marked overriding of the fragments and free motion.

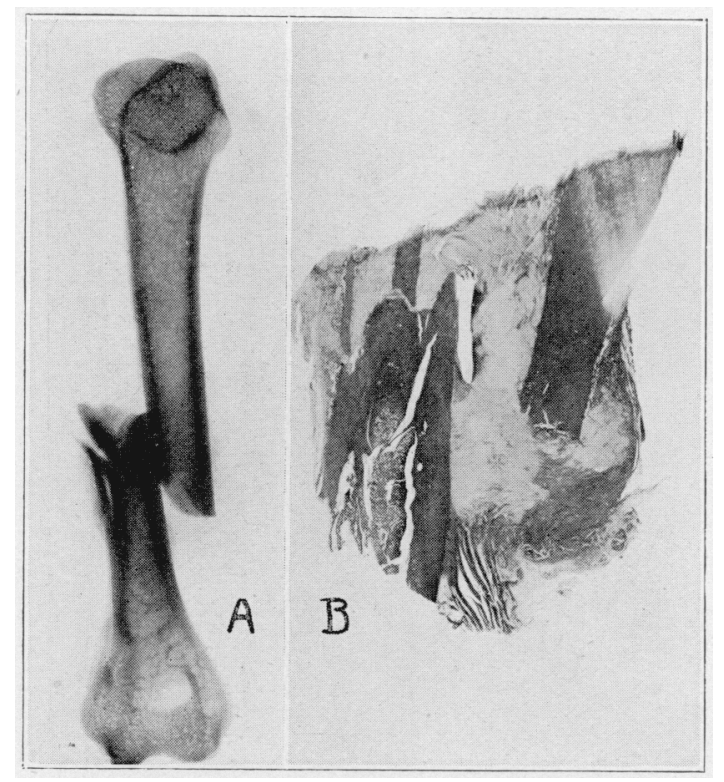

Fig. 8. $-A$, fractured humerus of Cat $7 ; B$, stained slide cut from fractured humerus of Cat 7.

Examination of the Stained Slidc.-The overlapping fragments were bound together by a dense mass of fibrous tissue and fibrocartilage which extended well over the end of each fragment. Hyaline cartilage was also present in this mass, especially near the cortex. The end of one fragment was comminuted. In this hyaline cartilage, close to the cortex, bone formation had begun, not only on the two cortices facing each other, but also to a lesser extent on the cortex on the far side. A few new trabeculae were visible in the marrow, here also apparently being formed from cartilage and fibrocartilage-the so-called internal callus. The new bone on the outside of the far cortex was forming under the fibrous periosteum in a sort of spindle shaped callus.

Summary.-There was cartilaginous callus, with tone formation beginning close to the cortex. 
Experiment 8.-Cat 8, a very large, full grown cat, was killed with illuminating gas, thirty-five days after fracture. Considerable overriding of the fragments was present, and a little motion. Union seemed to be well advanced.

Examination of the Stained Slide. - The overriding of the fragments amounted to about $1.5 \mathrm{~cm}$. The marrow canal of one fragment was open, that of the other was closed off by bone; but whether this was new bone or the old cortex cut obliquely it is impossible to say. A mass of cartilage lay between the two overriding fragments, and over the end of them. This cartilage was being ossified from each cortex. The ossification had proceeded to such an extent that fairly well formed marrow lay among the new trabeculae. Considerable internal callus was seen in the open ended fragment which appeared to

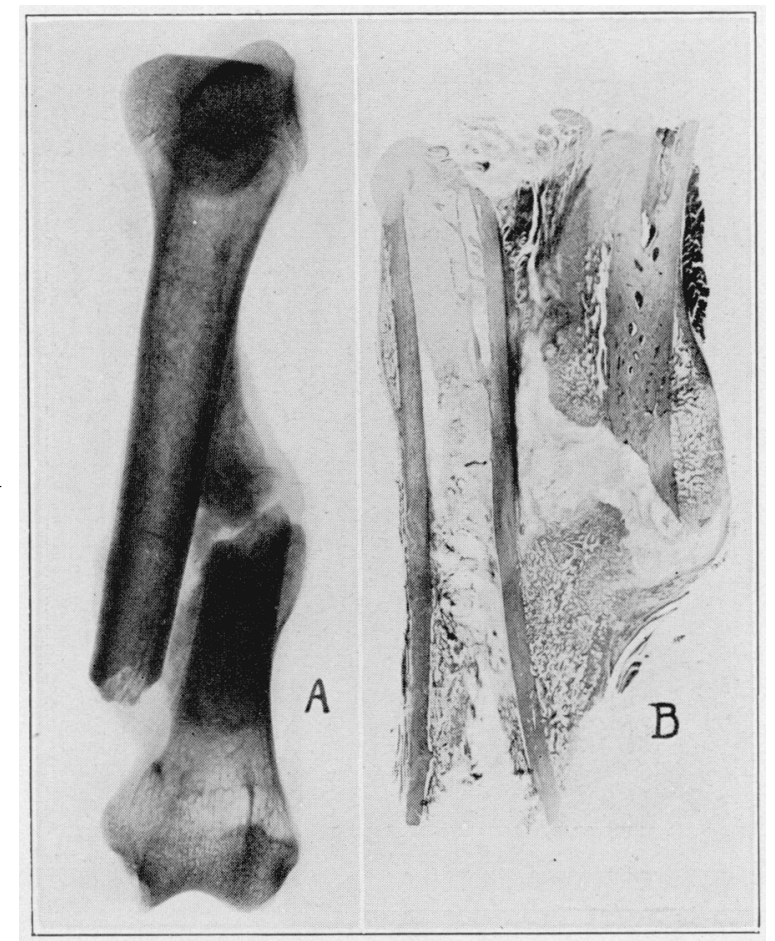

Fig. 9.- $A$, fractured humerus of Cat $8 ; B$, stained slide cut from fractured humerus of Cat 8.

have no connection with the external callus. No evidence appeared of any effort at remodeling the fragments, except in the closed off end of one, where new blood vessels apparently were pushing into the bone, and causing an absorption, but without any evidence of so-called rarefying osteitis.

The periosteum had suffered in the cutting, but it could be fairly well traced from the far side of the cortex of one fragment, covering the new bone in that situation, and then across the new cartilage and bone formation almost to the other fragment. The periosteum on the far side of the other cortex was practically without reaction and ended shortly after leaving the bone, from which it had been stripped for about a centimeter. This was probably due to the cutting of the block. 
Summary.-The fragments were fairly firmly welded together by a cartilaginous callus in which bone formation was well advanced. The periosteum did not appear to play any active part in the union.

ExPERIMENT 9.-Cat 9, a large, full grown animal, was killed with illuminating gas, forty-two days after the fracture. There was thickening about the seat of the fracture, and apparently firm bony union.

Examination of Stained Slide.-The two fragments, overriding about $1 \mathrm{~cm}$., were closed off at their ends by old bone. This closure was evidently due to the obliquity of the cutting knife. They were united by a mass of cartilage, in which new bone formation was fairly well advanced and over which periosteum stretched. Bone formation was especially noticeable close to the cortex

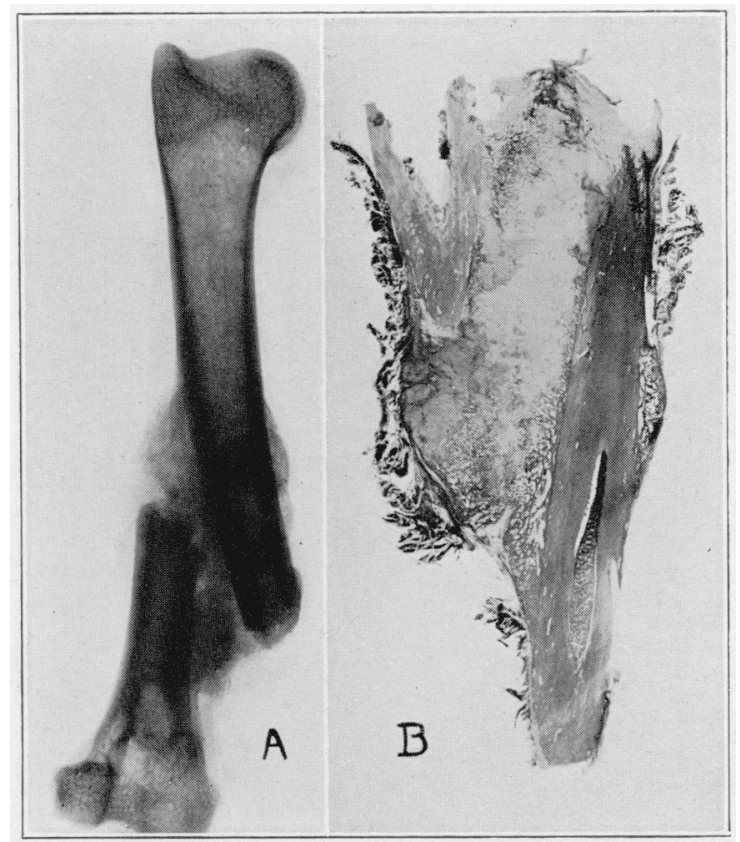

Fig. 10.- $-A$, fractured humerus of Cat $9 ; B$, stained slide cut from fractured humerus of Cat 9.

in the angle where the stripped-up periosteum left it to pass over to the other bone, but the periosteum itself was apparently not taking any active part in the bone formation. The mass of ossifying cartilage extended over the tips of the fragments. No evidence of any internal callus was seen.

Summary- - The overriding fragments were firmly welded by a mass of cartilage well advanced in ossification. The periosteum did not seem to be taking any part in the process.

EXPeriment 10.-Cat 10, an adult animal, was killed with illuminating gas, forty-nine days after fracture. Marked lateral displacement was present, and more than a centimeter of overriding. One sharp fragment seemed to have punctured the periosteum. The fragments moved a little on each other.

Nore: Instead of being put in liquor formaldehydi, the specimen was put in 5 per cent. nitric acid immediately, by mistake, and remained in it for four weeks. 
Examination of Stained Slide.-The fragments overrode to the extent of about $1.5 \mathrm{~cm}$. The end of each was closed off by dense fibrous tissue, underneath which was a rather thin layer of newly formed bone. In the fibrous tissue were rifts. In the central marrow canal of one bone and on the inner aspect of the cortex of the other, new trabeculae were present-an indication of internal callus.

The two fragments were bound together by a dense tissue, part of which was fibrous, and the rest looked like cartilage under low power magnification, but contained no cartilage cells that could be distinguished. New bone trabeculae were being formed in this tissue at its junction with the cortex.

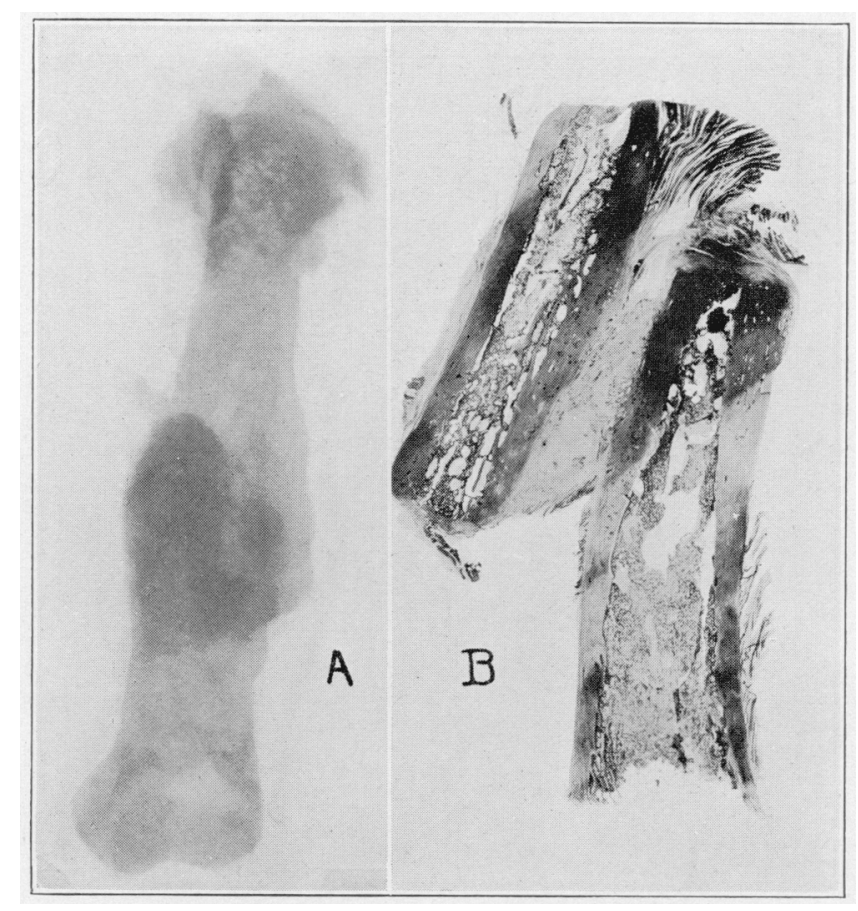

Fig. 11. $-A$, fractured humerus of Cat 10 , subsequent to decalcification; $B$, stained slide cut from fractured humerus of Cat 10.

Summary.-There was fibrous and cartilaginous callus in which bone formation was advancing. The state of the specimen precluded arriving at finer details.

Experiment 11.-Cat 11, a small animal but apparently an adult, was killed with illuminating gas, fifty-seven days after the fracture. There was marked deformity at the seat of the fracture but apparently solid bony union.

Note: Instead of being put into liquor formaldehydi, the specimen was put into 5 per cent. nitric acid by mistake and remained in it for three weeks.

Examination of Stained Slide.-The ends of both fragments were pointed, bone shutting off their marrow canals, but this was probably an artefact, caused by the angle of the microtome knife. They were welded together by a fusiform mass of cartilage well advanced in ossification. The fragments themselves were separated by an interval of about $0.5 \mathrm{~cm}$. Over the fusiform mass the peri- 
osteum stretched. The new bone was especially abundant in the immediate vicinity of the cortex, and ossification was also well advanced in the angle where the periosteum left the bone at a short distance from its end, but the periosteum itself did not appear to be taking any active part in the new bone formation. In the cartilage, blood vessels could be seen, giving a picture analogous to that seen in an epiphysis when ossification is taking place. The mass of bone and cartilage lay between the bones, as well as about their ends. There was no indication of any internal callus.

Summary.-Firm union had been accomplished by ossification of cartilaginous callus. In this union the periosteum appeared to be taking no active part.

Experiment 12.-Cat 12, a very large animal, was killed with illuminating gas, sixty-three days after the fracture. Considerable deformity was present at the seat of fracture, with solid union.

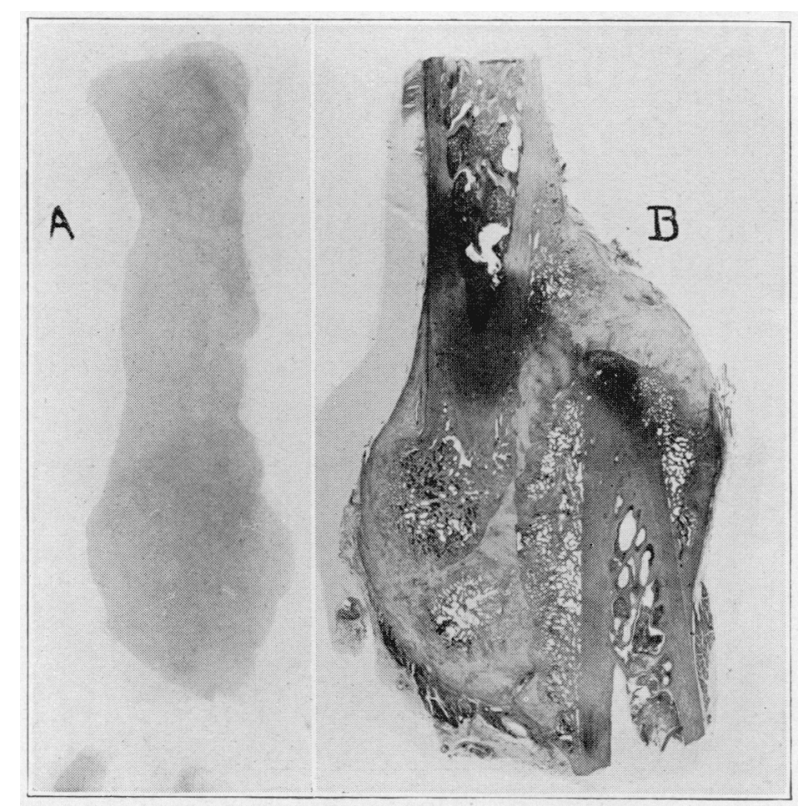

Fig. 12. $-A$, fractured humerus of Cat 11, subsequent to decalcification; $B$, stained slide cut from fractured humerus of Cat 11 .

Note: Like the two preceding, this specimen also was put into 5 per cent. nitric acid immediately, by mistake, and remained in it for three weeks.

Examination of Staned Slide.-The two fragments overlapped for about $2 \mathrm{~cm}$. The end of one had been caught obliquely by the microtome knife so that the cortex appeared to close the end of the central marrow canal. The marrow canal of the other fragment had been closed off by new bone.

The ends of the fragments, not in close apposition, were united by new bone and by partly ossified cartilage, and the cortex of each fragment contiguous to this uniting tissue was opening up, that is, was being converted into spongy bone, so that evidently the marrow canals of the two fragments already communicated through the bone meshwork. No evidences of so-called 


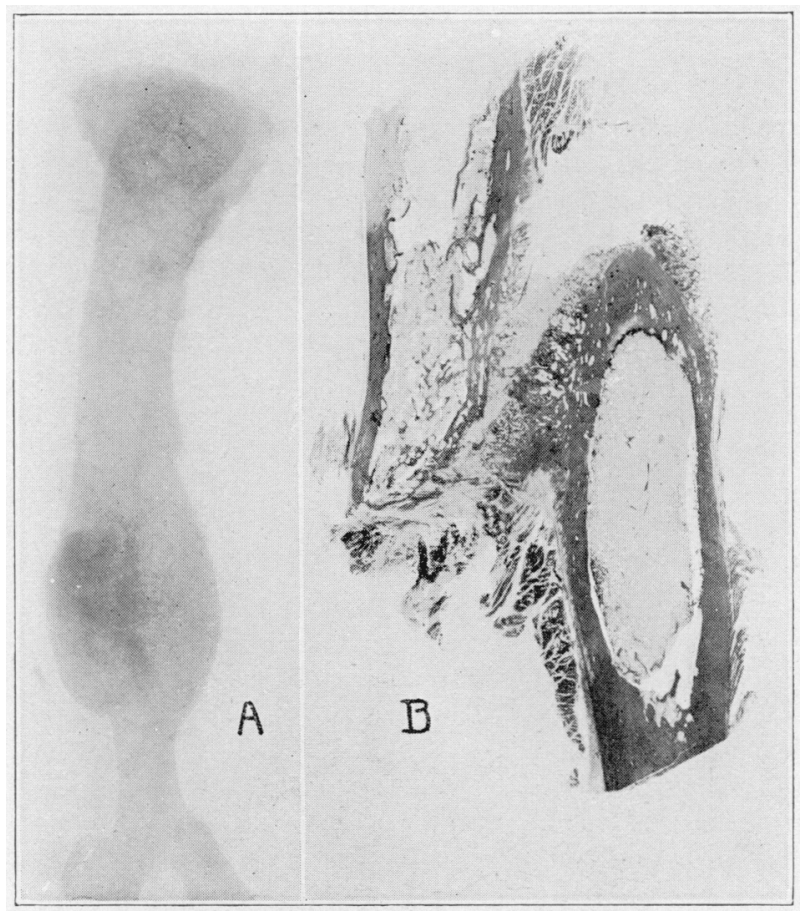

Fig. 13. - $A$, fractured humerus of Cat 12, subsequent to decalcification; $B$, stained slide cut from fractured humerus of Cat 12 .

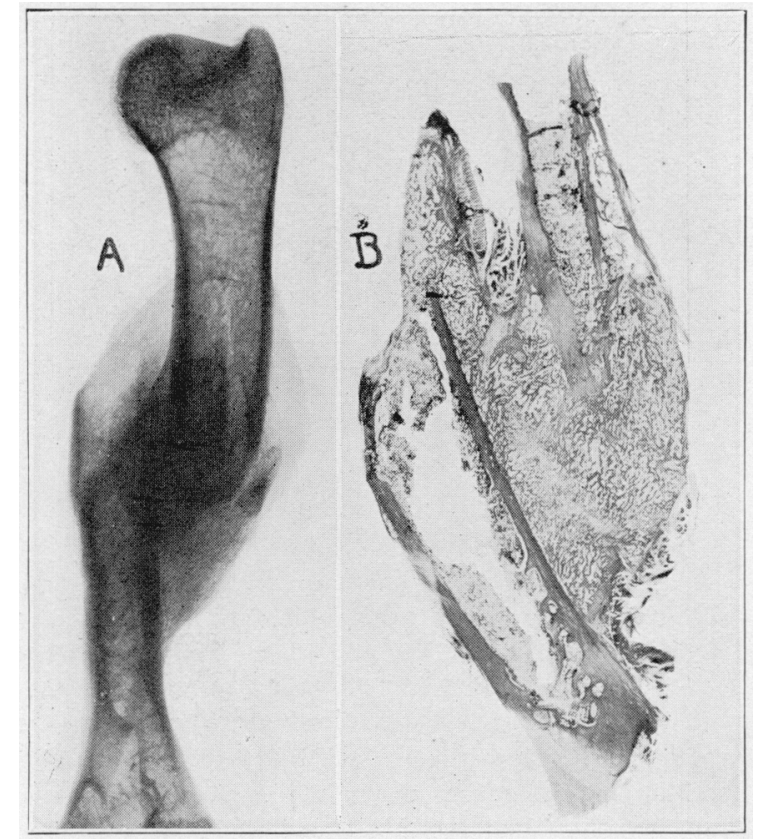

Fig. 14. $-A$, fractured humerus of Cat $13 ; B$, stained slide cut from fractured humerus of Cat 13. 
rarefying osteitis were present, however. In the immediate vicinity of this part of the cortex, the marrow canal of one fragment showed the new bone trabeculae of the internal calius, but not the marrow canal of the other. All about the closed end of the other fragment, bone trabeculae were forming in fibrous tissue.

Summary.-New bone from cartilage and fibrous tissue united the fragments laterally. There was rearrangement of the bony architecture. The rôle of internal callus was insignificant. The rôle of the periosteum was hard to distinguish.

EXPERIMENT 13.-Cat 13, a large animal, was killed with illuminating gas, seventy-one days after the fracture. Marked thickening was present at the site of fracture, with overriding and firm lony union.

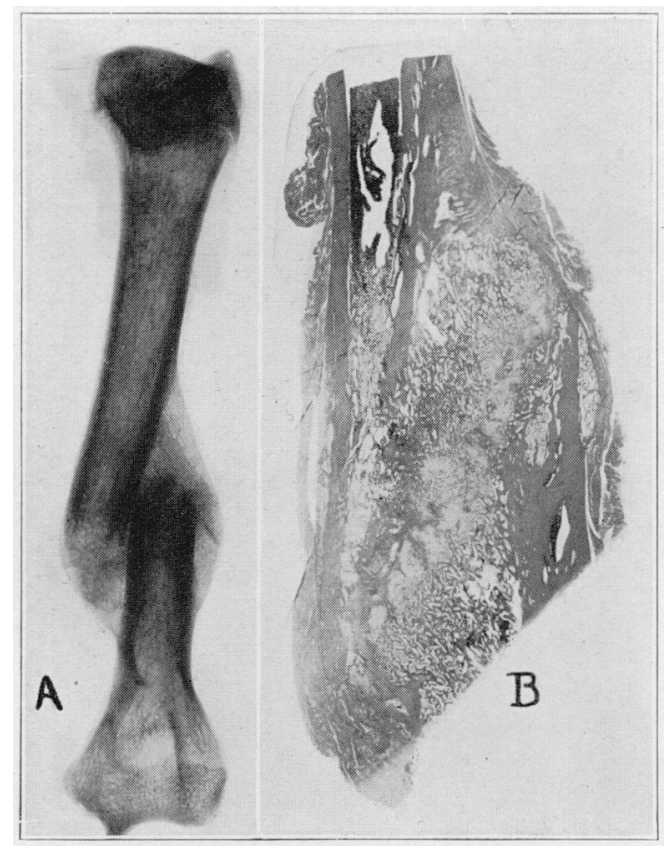

Fig. 15. $-A$, fractured humerus of Cat $14 ; B$, stained slide cut from fractured humerus of Cat 14.

Examination of Stained Slide.-The fragments overrode for about $0.5 \mathrm{~cm}$. and were separated laterally about the same amount. They were united laterally by a mass of newly formed bone, some of which was not yet completely ossified. No cartilage could be detected in this bone. The new bone covered the end of each fragment like a cap, and apparently its blood vessels communicated with those in the marrow canals in the fragments.

Summary.-New bone united the overlapping fragments laterally.

EXPFrimeNT 14.-Cat 14, a rather small animal, was killed with illuminating gas, seventy-seven days after the fracture. There was overriding of the bone ends, with firm union. 
Examination of Stained Slide.-The two fragments, overlapping for about a centimeter, had been firmly united by a mass of bone developed from cartilage, laid down between their overlapping cortices. The bone development was not yet completed, because a large amount of cartilage was still mixed up with the bone tissue, and rearrangement of the bone trabeculae was still progressing. Owing to the fact that one fragment had been caught obliquely by the microtome knife, its architecture could not be well made out; but study of the end of the other fragment demonstrated that the end of the cortex facing the first fragment had been torn down, and that spongy and irregular bone had replaced it, showing that its presence was no longer necessary. The cortex on the far side near its end had suffered slightly, and in one limited area was being replaced

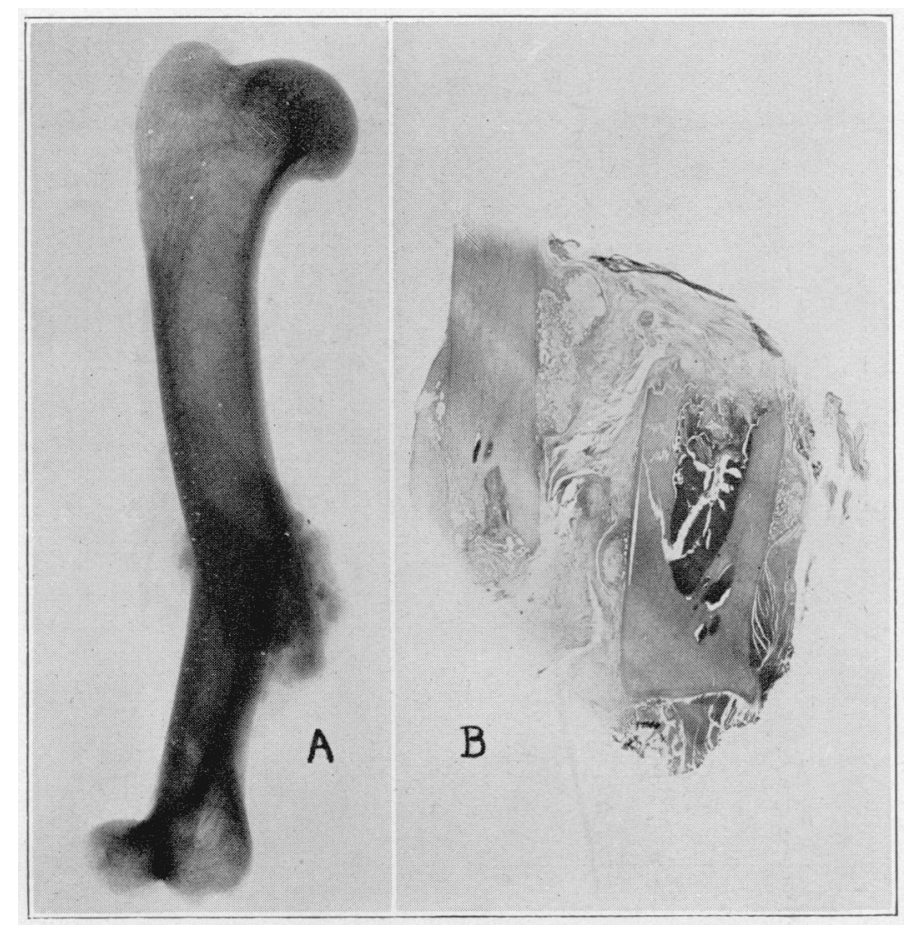

Fig. 16.- $A$, fractured humerus of Cat $15 ; B$, stained slide cut from fractured humerus of Cat 15.

by spongy bone. In this exact place new bone had been built up beneath the periosteum on the outside of the cortex.

Summary.-The overlapping ends of the fragments were united firmly by new bone, chiefly developed from cartilage. The architecture of the cortex was being rearranged.

\section{SECOND SERIES}

With Cat 15 begins a new series of operations. An incision was made on the lateral aspect of the fore leg and the dissection was carried to the periosteum. This was divided circularly, and the bone 
was fractured either with a Gigli saw or Liston bone forceps. The wound was then sutured, and a sterile dressing was applied. Infection occurred only once in the series.

EXPFriment 15.-Cat 15, a large, full grown animal, was killed with illuminating gas sixty-five days after the fracture. An incision had been made down to the bone; also an attempt, not very successful, had been made to divide the periosteum. The bone had been fractured with Liston bone forceps. Deep and superficial sutures had been made and collodion applied.

Free motion was present at the seat of fracture, with overriding. There was no sign of union.

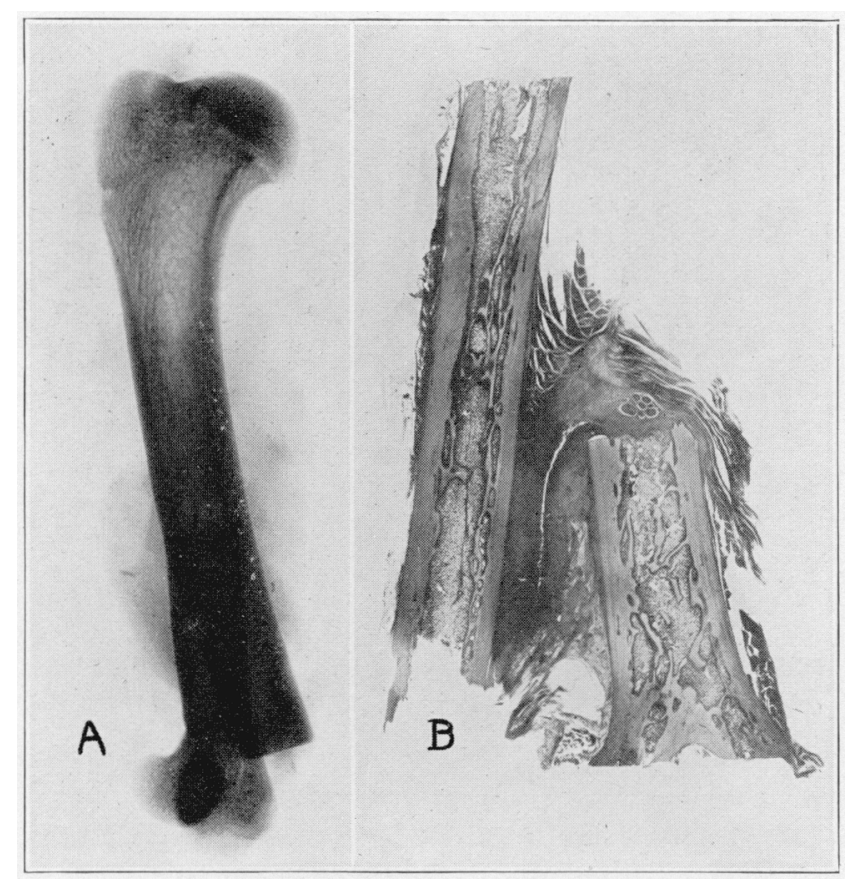

Fig. 17. $-A$, fractured humerus of $C a t 16 ; B$, stained slide cut from fractured humerus of Cat 16.

Examination of Stained Slide.-The specimen had been caught at an unsatisfactory angle by the microtome knife. One fragment showed its medullary canal, and in this canal new bone trabeculae could be seen. The other fragment showed the central medullary canal only at its extreme end, and here the new bone trabeculae were so abundant that they practically shut off the end of the canal. At the end of one cortex of the latter fragment, a cap of new bone was being formed out of cartilage. Each fragment showed new intracartilaginous bone formation, generally in irregular knobby areas on the outside of each cortex, but there was no bridge of bone and cartilage connecting the two fragments. On the outside of the cortex, the regular strips of new periosteal bone were missing, which were evident in the first series of operations. Irregular fibrous tissue covered the end of each fragment and bound the two 
fragments together; but, except immediately contiguous to the cortex, no new bone or cartilage could be discerned in this fibrous tissue. Through this connecting tissue and running across diagonally from bone to bone was a large cleft, or, better expressed, a series of clefts. The walls of this cleft were irregular and in places showed well marked villous appearance, but no definite cartilage.

Summary-There was formation of a false joint. The bones were united by fibrous tissue, and in this fibrous tissue was a series of rifts.

EXPERIMENT 16.-Cat 16, a large adult cat, was killed with chloroform, eleven days after the fracture. An incision was made as in Cat 15. Dissection was carried down almost to the bone. An aneurysm needle was passed about the bone, including some muscle tissue and the periosteum. A Gigli saw passed in the track of the aneurysm needle divided the bone and periosteum.

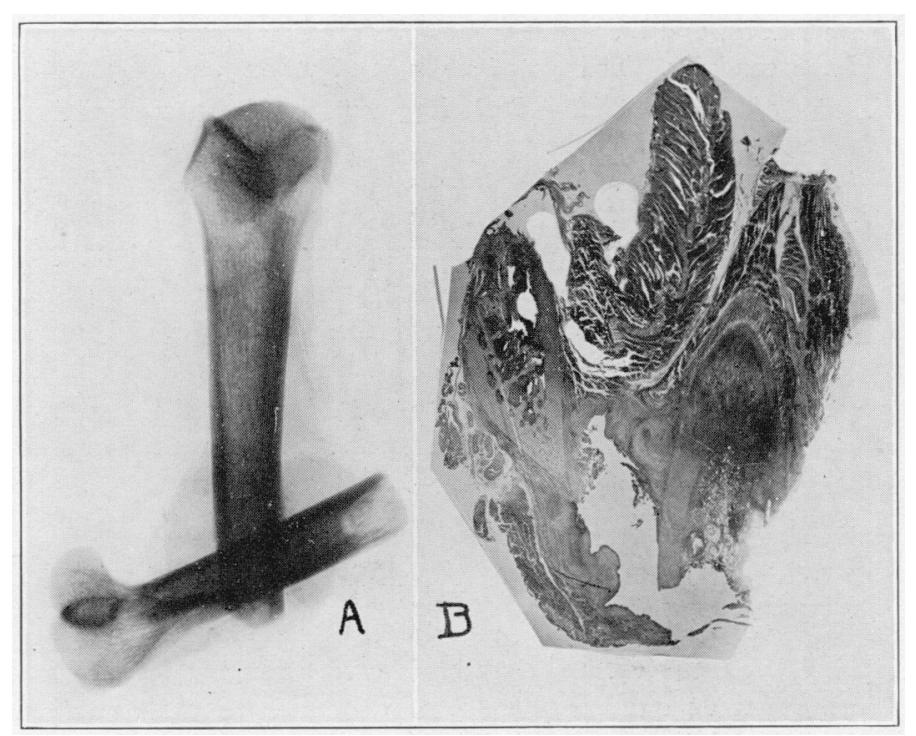

Fig. 18.- $A$, fractured humerus of Cat $17 ; B$, stained slide cut from fractured humerus of Cat 17.

The wound became infected, and the cat was killed. The old wound was opened, revealing a large subcutaneous pocket of pus. Whether or not this pus pocket communicated with the fracture was not determined. The fragments had overridden noticeably. The distal end of the proximal fragment was down almost level with the condyles. The fragments moved frcely on one another, and showed no sign of union.

The bones were removed, together with the surrounding tissues, were washed and then put into liquor formaldehydi.

Examination of Stained Slide.--The ends of the bones overlapped about $1.5 \mathrm{~cm}$., and were bound together by a dense hyaline, fibrous tissue which appeared to be metamorphosing into cartilage, although no distinct cartilage cells could be seen in it. The marrow canals of both fragments were open. That of one fragment was closed off by the hyaline, fibrous tissue; but as to the other canal nothing could be said, for everything had been cut by the 
knife, down to the end of the bone. In the fibrous tissue, and running almost parallel with the bones but slightly obliquely, was a distinct rift, as if a joint were being established. In the fibrous tissue on the apposed cortices, new bone formation was beginning, but on the cortices on the far side, no new bone was present, nor was there any evidence of the formation of an internal callus.

Summary.-There was probable infection. Apparently a false joint was in the process of formation.

EXPERIMENT 17.-Cat 17 was killed with chloroform, fifteen days after the fracture. The operation was the same as that performed on Cat 16 except that the saw broke during the operation, and the division of the bone was completed with Liston bone forceps.

The wound broke down and suppurated, necessitating chloroforming the cat after fifteen days. The bones were removed, with the surrounding tissue. They had overridden, and the distal end of the proximal fragment was at about the level of the condyles. There was no sign of union, and very free motion.

Examination of Stained Slide.-Both fragments had been caught at an angle by the microtome knife, so that exact details were hard to determine, but no union had taken place, and apparently the only effort at it was represented by a small amount of external callus on each cortex of each bone. There was an open space between the fragments lined by a tissue that had very much the appearance of synovial membrane.

Sumnary.-Suppuration was present, and there was practically no attempt at union.

ExPERIMENT 18.-Cat 18 was killed forty-five days after the fracture. There was circular division of the periosteum as with Cat 16, with division of the bone by a Gigli saw. When the cat was killed, the fragments were apparently firmly united in the presence of much callus.

Examination of Stained Slide.-The two fragments overlapped about 1.5 $\mathrm{cm}$. They were about $1 \mathrm{~cm}$. apart laterally, and their marrow canals were closed off by a very thin layer of new bone. This thin layer of bone was evidently being thickened up, for further intracartilaginous bone development could be seen going on outside of it. One fragment showed a few scattered trabeculae in its medullary canal, but neither fragment showed any internal callus in the shape of new bone on the inside of the cortex. There was practically no bone formation on the far side of the external aspect of either cortex. The two fragments, about a centimeter apart, were joined by a dense mass of new bone and cartilage, that is, by cartilage in which new bone formation was well advanced in the vicinity of the cortices, unossified cartilage separating the two strips of newly formed bone. Dividing this strip of cartilage through its whole extent, and running parallel to the bone, was an irregular but well defined slit or rift. This rift, bounded as it was by cartilage backed up by bone, and with its extreme ends closed off, gave an appearance strikingly analogous to that of a regular joint.

Summary.-There was formation of a new joint by means of a rift in the cartilaginous callus joining the fractured bones laterally.

Experiment 19.--Cat 19 was killed sixty-three days after the fracture. The same operation was performed as on Cat 16-circular division of the periosteum and bone with the Gigli saw. When the cat was killed, firm bony union with marked overriding was apparently present. 


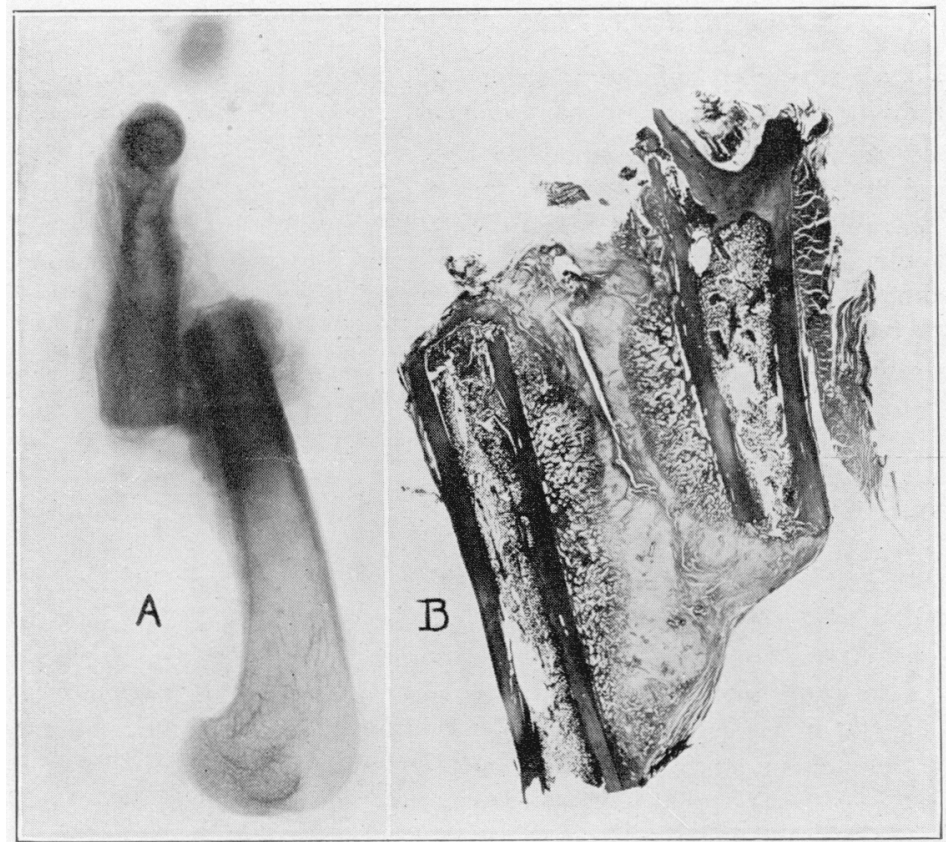

Fig. 19.- $A$, fractured humerus of Cat $18 ; B$, stained slide cut from fractured humerus of Cat 18.

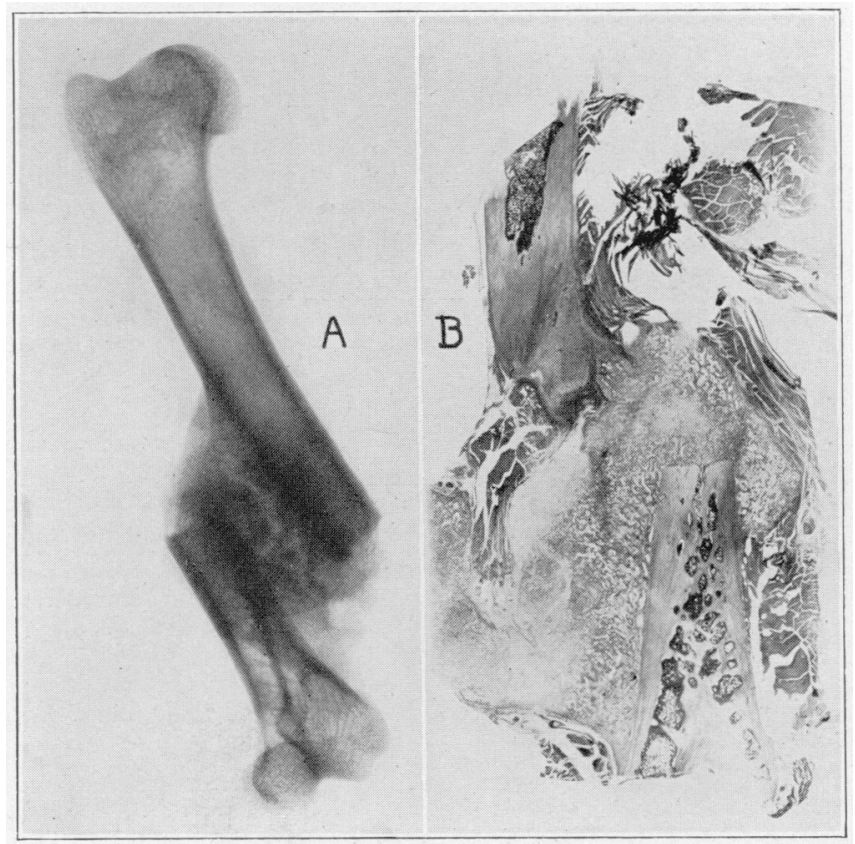

Fig. 20.- $A$, fractured humerus of Cat $19 ; B$, stained slide cut from fractured humerus of Cat 19. 
Examination of Stained Slide.-The ends of the bones had not overridden at all, but there was some lateral displacement at the seat of fracture. The ends of the bones had been caught obliquely by the microtome knife, so that it was impossible to say whether or not their marrow canals were still open. They were firmly united by a mass of new bone which had been formed from cartilage and was densely spongy in its texture. This new bone was continuous with that of the cortex in the neighborhood of the end of each fragment, as well as with the very end of each fragment itself.

Summary.-There was firm union of the fragments by bone developed from cartilage.

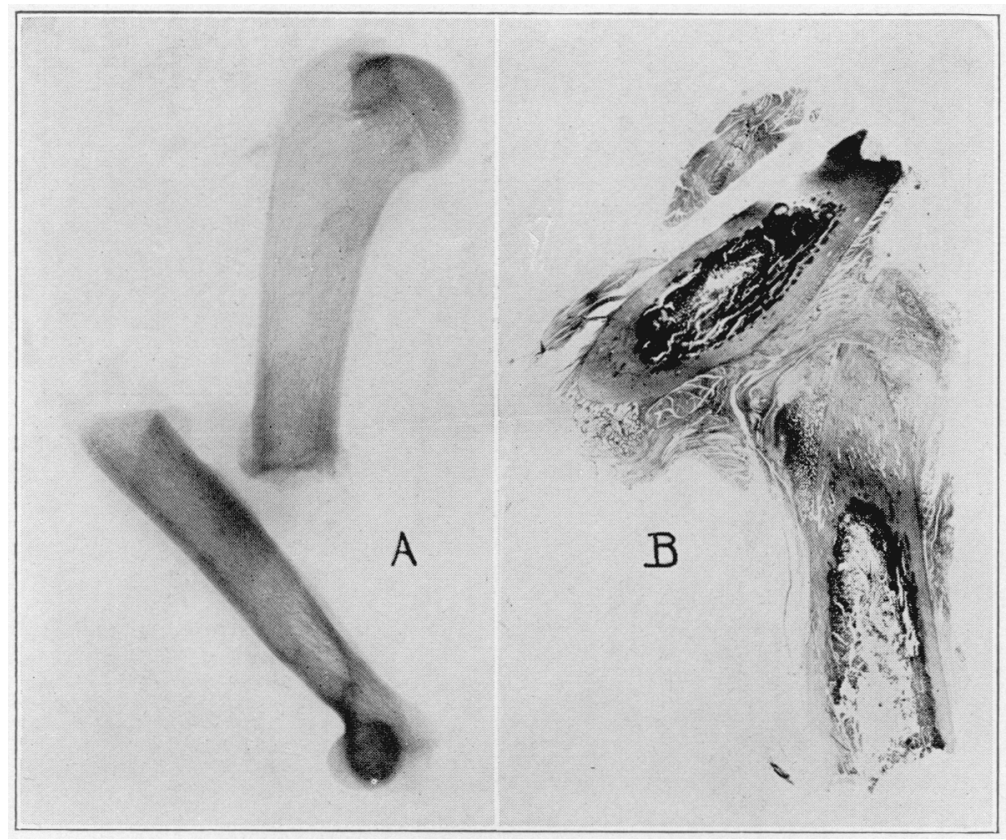

Fig. 21.- $A$, fractured humerus of Cat $20 ; B$, stained slide cut from fractured humerus of Cat 20 .

Experiment 20.-Cat 20 was killed thirty-six days after the fracture. The same operation was performed as on Cat 17 , the saw breaking, and the division of the bone being completed with Liston bone forceps.

When the cat was killed, the wound was healed, and the hair had grown over the site of operation. The bones, with the tissues immediately surrounding them, were removed. They were apparently overlapped about $2 \mathrm{~cm}$., and there was no sign at all of union.

Examination of Staincd Slide.-The two fragments articulated at an angle, or rather the end of one fragment articulated with the side of the other fragment at almost a right angle, about $2 \mathrm{~cm}$. from its extremity. The end of one fragment had been caught obliquely by the microtome knife so that the patency of its marrow canal could not be determined, but the marrow canal of the other was almost completely shut off with new bone trabeculae whose spaces were filled with dense fibrous tissue. Apparently these bone trabeculae were being 
formed from fibrous tissue, for within the marrow canal there was no evidence of endochondral bone formation. On the outside of the end of each cortex of this fragment, the stained slide showed, beneath the periosteum, a fairly regular semicircle of new bone, forming from cartilage, as if in the blind effort to accomplish the classical wiped joint usually found in the healing of fractures. But all this new bone was well encapsulated by fibrous tissue, and showed no tendency to spread across to the other fragment, being separated from it by very dense fibrous tissue which contained clefts or rifts. This dense fibrous tissue extended over the entire end of the fragment, forming a thick cap for it, and passing down among the trabeculae in the central marrow canal as noted above.

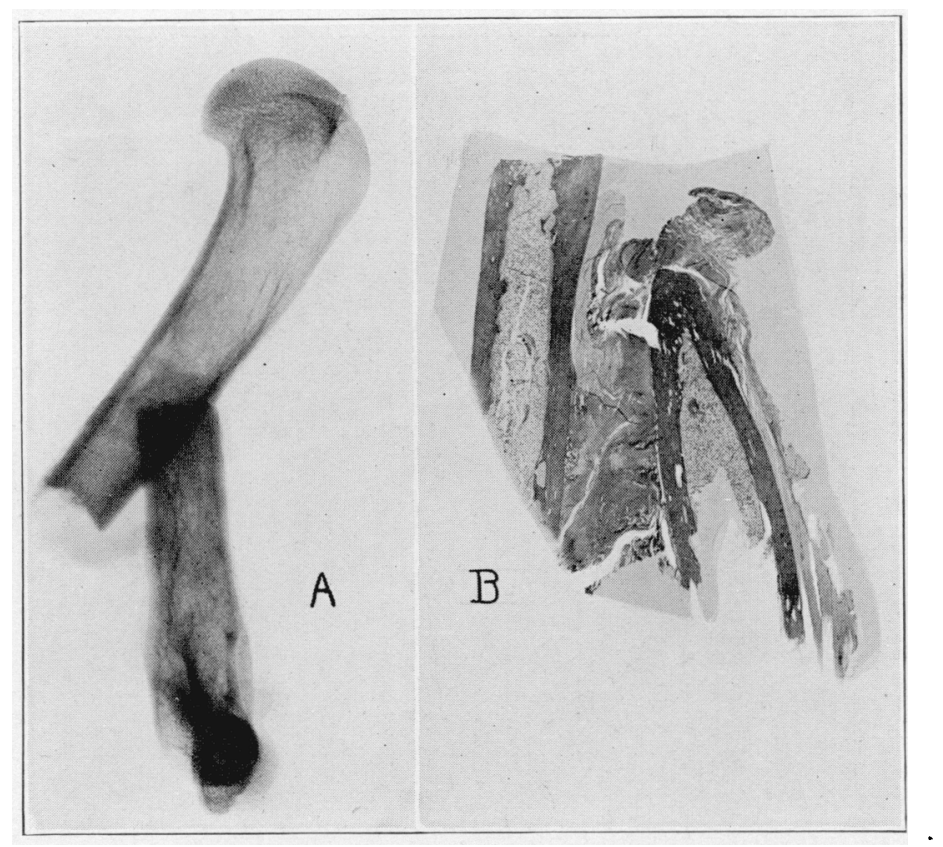

Fig. 22.- $A$, fractured humerus of Cat $21 ; B$, stained slide cut from fractured humerus of Cat 21.

The other fragment was capped on the outside of its conical end by new endochondral bone, spongy in its interior but denser at its periphery. This cap of bone was covered almost completely by rather dense fibrous tissue.

Summary.-There was the formation of a new joint between the end of one fragment and the lateral aspect of the other. Internal and external callus was present.

\section{THIRD SERIES}

In this series a longitudinal incision was made in the periosteum, and the right humerus was divided by Liston bone forceps.

Experiment 21.-. Cat 21 was killed forty-eight days after the fracture. A lateral incision was made on the fore leg; intermuscular dissection was carried down to the periosteum, and a longitudinal incision was made through the 
periosteum. The periosteum was separated from the 1:one; the bone was divided with Liston forceps, and was sutured with deep and superficial catgut sutures, and a collodion dressing applied.

When the cat was killed the wound was well healed and the hair had grown over it. Marked overriding of the fragments was present, but no sign of union.

Examination of Stained Slide.-The marrow canal of one fragment was open, and in the marrow, close to the end, were irregu'ar chips of bone or bone trabeculae, which for the most part appeared to be dead; but the nuclei of some stained well, so that one got the impression that they were partly chips of bone from the fracture being absorbed, and partly new bone building across the marrow canal. The ends of the cortex of this fragment were ragged,

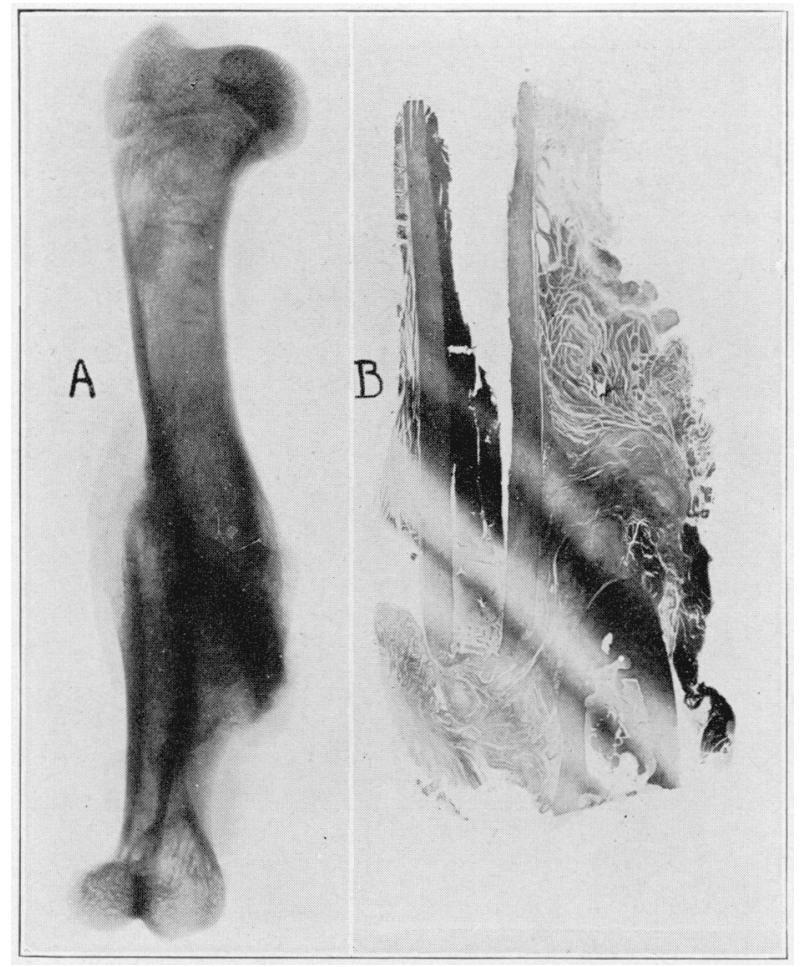

Fig. 23.- $A$, fractured humerus of $C$ at $22 ; B$, stained slide cut from fractured humerus of Cat 22.

and the bone of the cortex on the far side from the other fragment stained poorly, while that of the cortex toward the other fragment stained much more distinctly. Across the end of this cortex and extending about half way across the end of the marrow canal was dense fibrous tissue, and this fibrous tissue ran across to the other fragment, showing in its structure a marked cartilaginous element as it neared the cortex of the latter. In this cartilage, formation of bone trabeculae was beginning, but, whether hecause of an artefact or not, these trabeculae were not apposed to the cortex. A small irregular slit lay between the intracartilaginous bone formation and the cortex. 
The end of the other fragment had been caught at an angle by the microtome knife, so that the patency of the marrow canal could not be determined. Fibrous tissue extended from near the end of this fragment to the cortex of the other, and this tissue also showed much cartilage in the region of the latter cortex, with new bone trabeculae developing close to the cortical bone. These trabeculae were not separated from the cortex as were the others.

In the connecting tissue were irregular rifts or rents, one of them extending from a spot over the open marrow canal of the one fragment diagonally across, almost to the cortex of the other; and in this rent, as in some of the others, were organized masses of fibrin, with the typical shape of synovial villi. Indeed, the sides of the cleft might have been mistaken for synovial membrane.

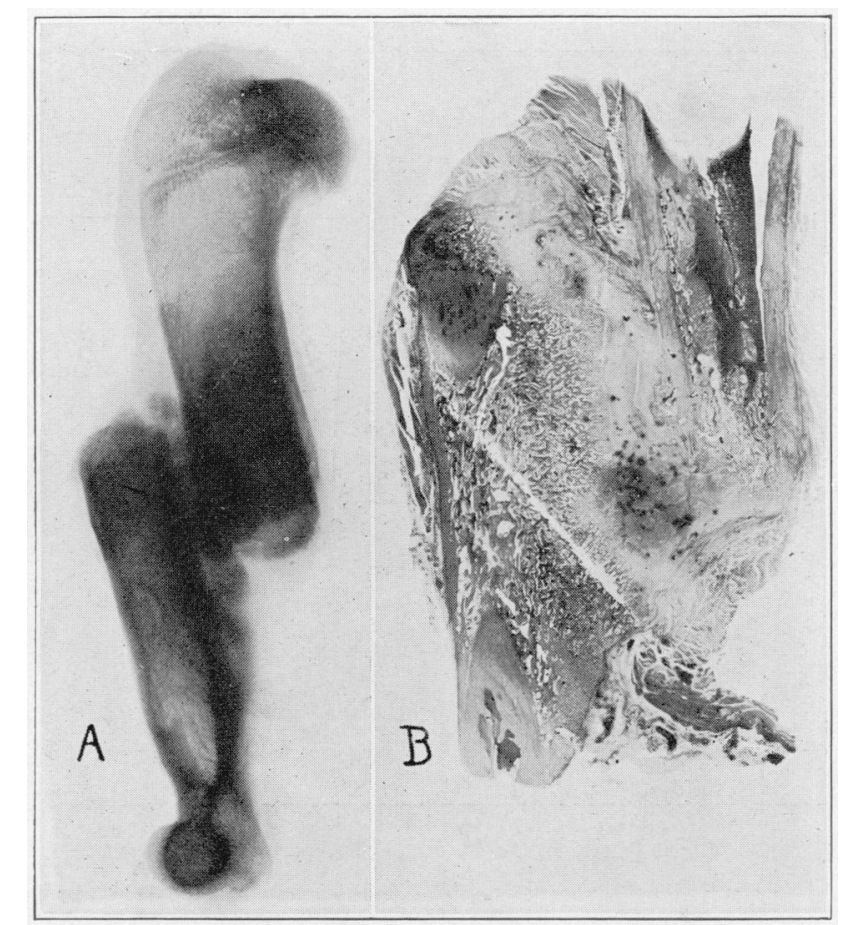

Fig. 24.- $A$, fractured humerus of Cat $23 ; B$, stained slide cut from fractured humerus of Cat 23.

Summary-In spite of the small intracartilaginous bone development, there was no indication in this specimen that bony union ever would take place. Everything pointed to the establishment of a new joint.

Experiment 22.-Cat 22 was killed sixty-two days after the fracture. The same operation was performed as on Cat 21 . The animal was young. When it was killed there was no sign of infection. The wound had healcd and the fur had grown over it. Apparently, there was firm uinon, with a large amount of callus.

Examination of Stained Slide.-The fragments overlapped and the end of one had been caught by the microtome knife obliguely, so that whether or not its marrow canal had been shut off by new bone could not be determined. On 
the side of its extreme end, toward the other fragment, was a fairly large mass of newly developing intracartilaginous bone, and some distance from the end, also on this side, toward the other fragment and continuous with the cortical bone, was a narrow strip of new intracartilaginous bone still in the stage of development. Dense fibrous tissue in bundles separated this fragment from the other, and in this fibrous tissue were long and well defined rents. In places along the side of these rents, organizing fibrin could be seen with an appearance typical of synovial villi. Apparently, the formation of a new joint was rather well advanced.

The end of the marrow canal of the other fragment was well walled off with new bone, and the fibrous tissue dividing the two fragments passed over this new bone. Over the end of this fragment in the fibrous tissue, the rents

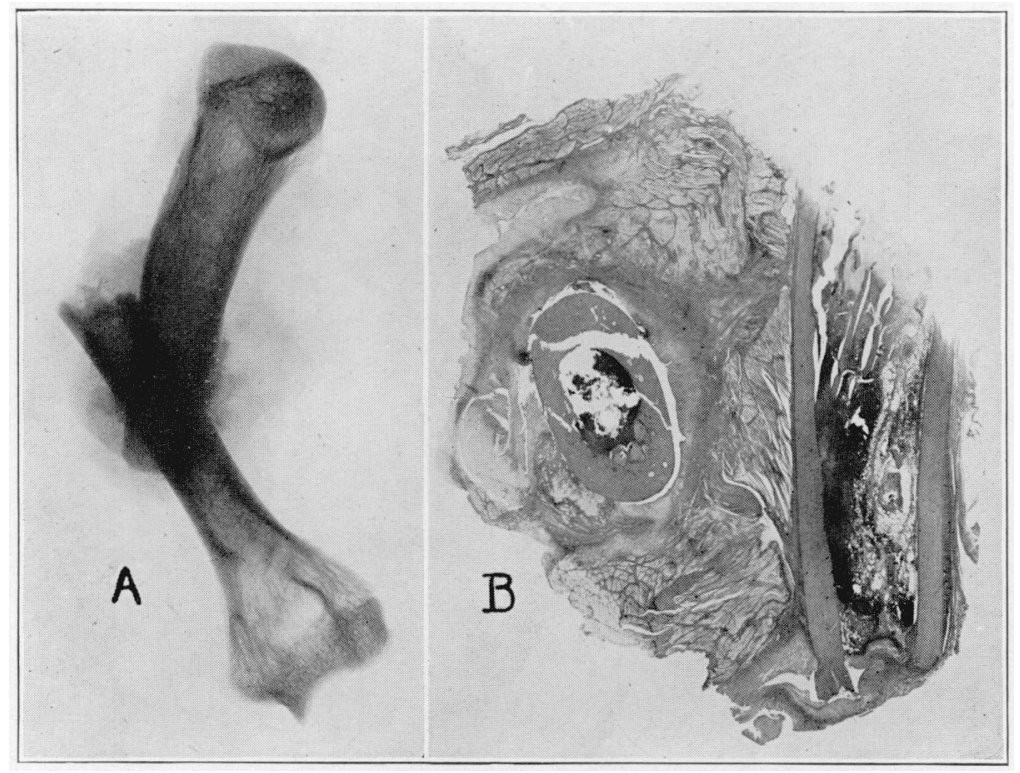

Fig. 25.-A, fractured humerus of Cat $24 ; B$, stained slide cut from fractured humerus of Cat 24.

were continued with their villous formation. The sides of the cortex of this fragment showed no new bone, but in the fibrous tissue at the extreme end of this fragment, and separated from it by a small interval, was a small mass of new intracartilaginous bone.

Summary. - There was new joint formation. The bones were united by fibrous tissue containing clefts or rents.

EXPERIMENT 23.-Cat 23 was killed after forty-one days. It was evidently quite a young cat. The operation was the same as that performed on the two preceding cats. When the animal was killed, there was no sign of infection and the hair had grown over the wound. Apparently, firm union was present, with considerable callus.

Examination of Stained Slide.-The fragments overlapped about a centimeter, with an interval of about $0.5 \mathrm{~cm}$. laterally. The marrow canals of both 
bones were almost completely shut off by new bone trabeculae with a rather dense spongy structure. The two fragments were joined by a mass of cartilage and bone which was not homogeneous in structure. Near one fragment it consisted almost exclusively of cartilage and near the other fragment of bone. This mass of cartilage extended over the end of each fragment, and over almost the entire mass, the periosteum could be traced. New bone trabeculae, the so-called internal callus, were seen on the inner aspect of the cortex of one fragment, and in its central canal.

Summary.-There was cartilaginous callus, binding the two bones together laterally. Ossification of this cartilage was well advanced. The ossification was proceeding from the cortices, and apparently in time would be complete.

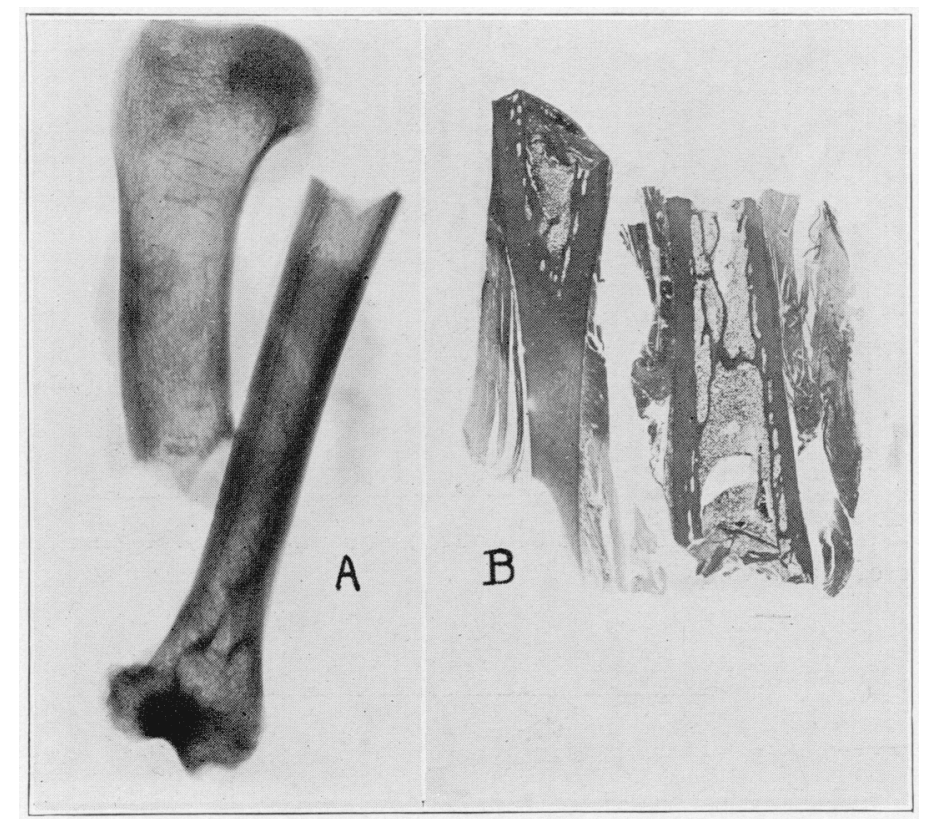

Fig. 26.- $A$, fractured humerus of Cat $25 ; B$, stained slide cut from fractured humerus of Cat 25 .

Experiment 24.-Cat 24 was killed after twenty-two days. The same operation was performed as on the three preceding cats. When the cat was killed, the wound in the skin was healed. The fragments had overridden and there was no evidence of union. On cutting down to the fracture a focus of pus was opened, in which the distal end of the proximal fragment lay bare and rough.

Examination of Stained Slide.-The fragments had been cut at such an angle by the knife that little could be told as to topography. Each fragment showed beginning endochondral bone formation on the outside of its cortex, but no attempt at union of the two fragments was evident. They were separated by an interval of about $0.5 \mathrm{~cm}$., and this interval was occupied by muscle and fibrous tissue in rather loose bundles, with many rifts.

Summary.-While it was too early to say positively, apparently the bones would not have united in this case. Infection about the end of one fragment. 


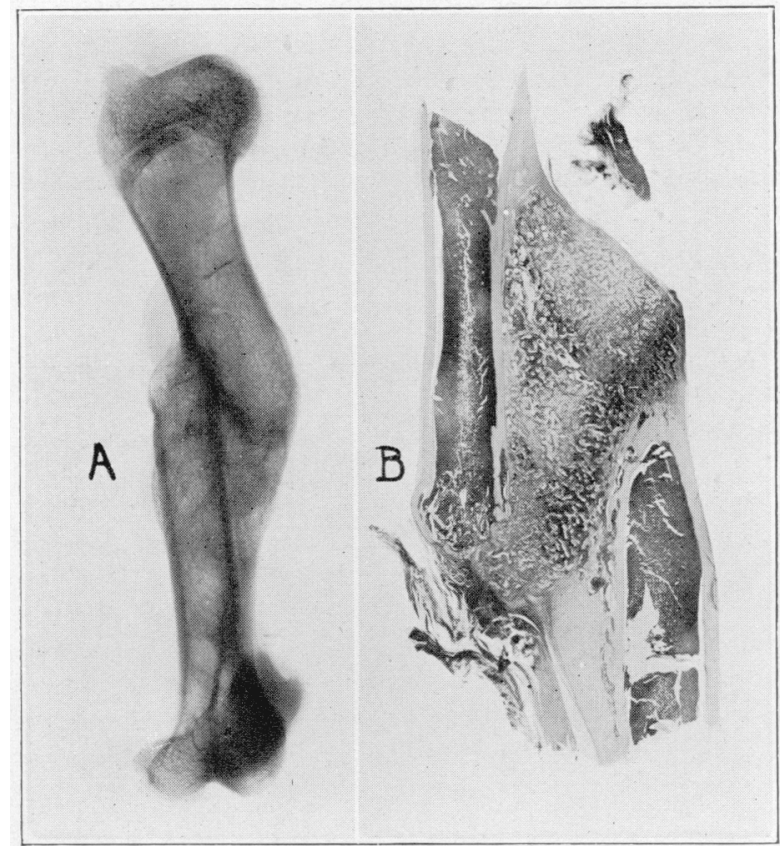

Fig. 27.- $A$, fractured humerus of Cat $26 ; B$, stained slide cut from fractured humerus of Cat 26.

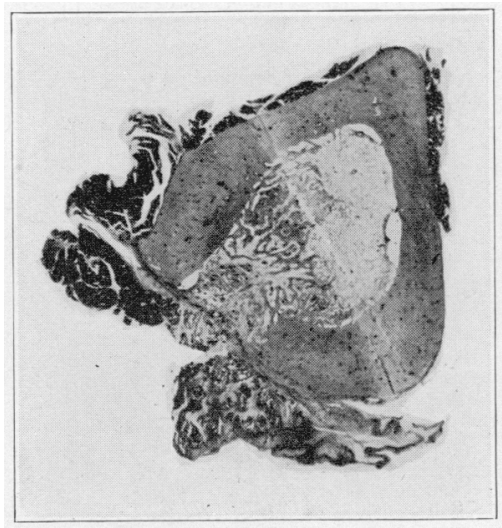

Fig. 28.-Cross section of tibia of cat, showing trabeculae forming in the marrow beneath the hole made in the cortex; $\times 4$. 
Experiment 25.-Cat 25 died after four days. The operation was the same as that performed on the last four cats. The periosteum was separated from the bone with difficulty. The cat died of an unknown disease. There was no sign of infection about the wound. Marked ecchymosis was present, and the fragments were loose.

Examination of Stained Slide.-The end of each marrow canal was shut off by a blood clot, and in one of these clots were a number of small spicules of bone, evidently broken off at the time of fracture. The periosteum was thickened, and in the neighborhood of the fractured end hemorrhage had taken place beneath it.

Summary.-There was hemorrhage in the marrow, and under the periosteum.

Experiment 26.-Cat 26 was killed after fifty-five days. The same operation was performed as on the preceding five cats. When the cat was killed the wound had healed, and the fur had grown over it. Moderate callus was present, with firm union.

Examination of Stained Slide.-The fragments had overridden somewhat less. than a centimeter, and laterally were about $0.5 \mathrm{~cm}$. apart. The end of one bone had been caught at an angle by the microtome knife, so that the cortex was pointed, and shut off the marrow canal in the slide. Whether or not the canal actually was shut off, it was impossible to tell. The marrow canal of the other fragment was partially shut off by new bone trabeculae. A few scattered trabeculae were also seen in the marrow in the immediate vicinity of this attempt at closing off. The overlapping fragments were tightly welded together by a mass of new bone, which evidently had been developed from cartilage, but there was no new bone on the off side of either fragment, and no evidence of any internal callus - no new bone trabeculae on the inside of the cortex. The new bone callus was continuous directly with the apposed cortices. The periosteum was continuous over much of the new bone, but on account of the stripping of the soft parts from the specimen on the slide, its continuity could not certainly be determined.

Summary:-There was firm bony union, apparently through the medium of cartilage. The new bone was directly continuous with that of the apposed cortices.

\section{CCMMENT}

These three sets of experiments were undertaken to demonstrate the truth of a theory which I have taught my classes for a number of years, namely, that after a fracture, the periosteum serves as a bridge in which nature builds bone, and that nonunion is usually due to the absence of this bridge. ${ }^{1}$ Not only do the experiments fail to demonstrate this, but they show that the theory was false. In none of the slides was there any evidence of any active part taken by the periosteum in the actual formation of new bone, and yet the most cursory inspection of the results demonstrates that the periosteum must play an important rôle of some kind, for where it was divided, there nonunion regularly resulted. The exact rôle of the periosteum in bone formation, and especially in the healing of fractures, has been the subject of much discussion. Indeed, the whole subject of the formation of

1. Ely, L. W.: The Formation of Bone, Ann. Surg. 69:225 (March) 1919. 
bone is still far from settled. These experiments throw light on both problems; but before considering them, we may profitably spend some time on a general study of bone formation. The study cannot be opened better than by an accurate definition of the terms employed.

Bone is an animal substance composed of organic material consisting of cells and intercellular substance, the latter impregnated with salts of lime and magnesium.

Marrow is the soft tissue within the bone-all the soft tissue within the bone, except the bone cells themselves. Its situation, not its composition, determines its name. Wherever there is bone there is marrow, and no matter what the composition of a tissue may be, if it is not situated within the bone, it is not marrow. Thus, small pockets of tissue with all the characteristics of marrow are occasionally seen in the region of the joints, on the outside of the cortex, immediately under the periosteum; but this is not marrow.

Periosteum is the tissue which covers bone in all situations not covered by the articular cartilage. As with the marrow, the situation of this tissue determines its name, not its structure. It usually consists of fibrous tissue, but in places it may consist of cartilage or of fibrocartilage.

If one looks through a microscope at the periosteum and the cortex of a growing bone, that is, of a bone of a child, one will see, lying on the cortex, numbers of bone cells or of osteoblasts. The trabeculae of the bone within the shaft present the same appearance whether they are being built up or torn down. These cells on the outside of the cortex, in a sense, may be said to be part of the periosteum, but really they have nothing whatever to do with it. They belong to the bone on which they lie. Nevertheless, they are responsible for the widely he'd opinion that the periosteum has two layers in its structure. Ollier first promulgated this theory, and poetically likened the periosteum to the bark of a tree, with its cambium layer. His theory gained almost universal acceptance until MacEwen challenged it a few years ago.

In the quiescent bone of the adult, nothing like a second layer of the periosteum can be made out. This subject is really not a question for debate. We cannot assume the presence of two layers because our clinical observation teaches us they should be there, and as far as I have been able to find out, no evidence other than clinical ever has been adduced for the presence of two layers of the periosteum in the adult bone.

Fibers of the periosteum run down into the bone cortex; but, as soon as they enter the bone, they cease to be part of the periosteum, and become part of the marrow.

Cartilage is a connective tissue consisting of cells and of a homogeneous or fibrillar basement substance impregnated with chondromucin. 
Typical cartilage is easily identified; but in certain cases the identification is only possible by recognizing the peculiar cartilage cells in their capsules. When these appear in fibrous tissue, we call the tissue fibrocartilage.

\section{THE FORMATION OF BONE}

Two theories have been held as to the formation of bone in general. According to the first, the metablastic, the members of the connective tissue group have the inherent power to change from one to another under certain circumstances, without the influence of any active outside agent. This theory has been almost abandoned, and has been replaced by the osteoblastic theory. According to this theory, bone is formed as the result of the action of a bone forming cell, the osteoblast. We assume that there is such a cell, but we do not know its derivation, and we have no means of identifying it under the microscope. It is supposed to be a small cell, with a deeply staining, round or polyhedral nucleus, frequently seen on the borders of bone trabeculae. When we see such cells on the trabeculae, we are wont to say that they are osteoblasts, and that bone is being built up in this situation. This, however, is not. always the case. Similar cells are seen in that situation when we know very well that the bone is being torn down. Moschcowitz ${ }^{2}$ says that the osteoblast is simply a differentiated endothelial cell from the wall of the blood vessel. At any rate, unless the osteoblast is the same thing as a cartilage cell, it must be brought to the tissue to be converted into bone, either in the blood stream or in the wall of the blood vessel, for bone formation never begins in cartilage, or, for that matter, in any other tissue, until the blood vessel pushes its way in.

We assume, then, some specific cell, the osteoblast, as the active agent in the formation of bone-the builder, so to speak. The next question is: Out of what is bone built? It may evidently be built out of one of a number of materials. It may be built out of cartilageintracartilaginous formation. It may be built out of fibrous tissueintramembranous bone formation. Apparently, bone may also be manufactured out of amorphous or granular necrotic material, as in old inflammatory processes in lymph nodes, or in kidneys whose arteries have been tied off. ${ }^{3}$

The third thing that is necessary for bone formation is a stimulus, pathologic or physiologic, as the case may be. Function is a stimulus, as is the mere presence of bone. If a piece of bone is removed from a live animal, and then if it is immediately buried in the same animal,

2. Moschcowitz, Eli: The Relation of Osteogenesis to Ossification, Bull. Johns Hopkins Hosp. 27:71 (March) 1916.

3. Liek: Zur Frage der heteroplastischen Knochenbildung, Arch. f. klin. Chir. 80:279, 1906. 
the bone and its contained marrow die.* Whatever happens thereafter in that piece of bone and marrow, therefore, must be the result of activity from the surrounding tissues. The first thing that happens is the pushing in of blood vessels from these tissues, and, if the fragment is covered in any part of periosteum, at that part vascularization first takes place.

Following the penetration of the blood ves:els, two distinct and opposite processes start in this sterile, dead piece of bone; on the one hand, rebuilding with new, live bone, and on the other hand, clearing away and absorption of the fragment. According to circumstances, one or the other of these processes will prevail, and the fragment will persist and even, in certain circumstances, increase in size, or it will disappear. The mere presence of the dead bone causes new bone to be formed (one stimu'us), but if there is no function (a second stimulus) absorption will exceed rebuilding, and the fragment eventually will disappear.

A third stimulus is irritation, as for instance, about an old suppurative osteomyelitis. Normal growth carries with it a fourth scimulus, whose existence we recognize, but whose nature we do not understand. We note that, at a certain period of existence, the blood vessel penetrates the cylinder of cartilage or the epiphysis, and initiates ossification, and that until full growth is attained, nature continues to lay down new bone on the outside of the cortex, and then ceases. Just what starts this physiologic bone growth, and just why it stops, we do not know. We observe it, and let it go at that. But wherever bone is being formed, the blood vessel is the active agent in the process.

We see then that bone may be formed either in the marrow or, perhaps, in the periosteum at the surface; but neither of these two tissues actually forms bone, and bone may be formed without either of them, as in cartilage.

It is well known that the ends of the cortex of a fractured bone possess in themselves little or no power of repair. If a hole is bored in the cortex of a long bone of a laboratory animal, the fractured end of the cortex takes very little part in the subsequent healing. Nature does not simply bridge across the hole in the cortex with new bone, as one would think, but she carries out her purpose by means of an internal and an external callus.

The external callus is small in amount, and consists of scattered trabeculae, mostly in the immediate neighborhood of the cortex beneath the periosteum. Where the hole was made in the periosteum, that is,

4. Ely, L. W., and Cowan, J. F.: A Study of Buried Bone, J. Orthop. Surg. 1:100 (Feb) 1919; An Experimental Study of Buried Bone, Ann. Surg. 70: 747 (Dec.) 1919. 
immediately over the hole in the bone, there the formation of bone occurs quite late. The major part of the healing is brought about by the so-called internal callus, that is, by bone trabeculae laid down in fibrous tissue in the marrow, and connecting with the inner aspect of the cortex. This makes a bridge of spongy bone in the marrow across the hole, whose trabeculae connect through the hole, by trabeculae laid down in fibrous tissue and perhaps in cartilage, with the trabeculae in the external callus. The resulting mass of callus of spongy bone has been likened in shape, by E. H. Nichols, to a collar button, with its large flange in the marrow, and its small flange in the periosteum. The connecting shank slowly increases in density until it fills up the hole, but does not establish continuity with the cortical bone at its sicle until a very late period. In other words, the cortical bone about the hole has played a passive part in the whole process. Everything has been done from the internal and external aspect of the cortex, in the marrow and beneath the periosteum.

We have no means of ascertaining how nearly the foregoing process is imitated in an accurately adjusted fracture of a long bone. The shank of the collar button is probably infinitesimal in thickness, and the roentgen rays indicate that the large flange is not in the marrow but in the periosteum. In fact, the whole essential part of the union seems to take place in, or under, the periosteum, and this roentgenographic phenomenon has gone far to strengthen the theory of the "bone forming" function of the periosteum.

That the periosteum plays an important rôle in the healing of fractures is evidenced by other facts, notably by the fact that nonunion is notoriously frequent in those bones or portions of bone not covered by periosteum: e. g., the neck of the femur, the head of the radius, and perhaps the carpal navicular in the region where it is usually fractured. On the other hand, we know that even in these fractures, if we can hold the fractured surfaces firmly together in complete immobility, union may be expected. This union could take place in only two ways, namely, by direct union between the fractured surfaces or by the formation of an internal callus. Apparently, an external callus does not form in the absence of the periosteum. In other words, in the absence of the periosteum, firm apposition and absolute immobility are necessary for union; in the presence of periosteum, they are not.

Nature has the greatest difficulty in bridging the smallest space with bone, and clinically it appears that some function of the periosteum 1s concerned in throwing the first bridge across. Just what this function $1 \mathrm{~s}$, has been the subject of much dispute.

There is a widely accepted theory that two raw bony surfaces brought together will unite. As has been said, they will not unite 
unless held firmly together in immobility. This is true not only of iractures but also of resections. After resections also, two processes are set in motion, one of joint building, and the other of ankylosis. In the human subject, the knee is about the only large joint in which bony ankylosis regularly can be obtained. In the others, fibrous ankylosis usually follows a resection. In the knee, two extensive bony surfaces can be brought into close apposition, and can be held firmly together. In other joints, these indications cannot be fulfilled. The elements of extensive apposition and immobility must be the determining factors in the human knee, for after resection of the dog's knee, bony ankylosis is very hard, to secure. A new joint usually results. 5

The first thing that attracts our attention in a consideration of the results of the experiments is the difference in the proportion of bony union to false joint in three series. In the first series, that with simple fracture, bony union regularly resulted if the cat was permitted to live for five weeks. In the second series, in which the periosteum was divided circularly, nonunion was the rule. Bony union took place in only one cat of this series. In the third series, that in which the periosteum was slit, bony union was about as frequent as new joint formation. From these facts the first conclusion to be drawn is:

1. The periosteum has a function to perform in the healing of fractures. The periosteum is not indispensable, for union may take place when it is slit or divided.

The next thing that interests us is the exact method of union. The specimens throw much light on this. In the first place, we note an entire absence of any bone-forming action in the periosteum. It is not even serving as a bridge or scaffold for the formation of bone, a function which I have persistently assigned to it. Its whole function seems to be to protect, to contain the soft callus between the fragments, to hold 1t against the fragments, so to speak. The specimens show that MacEwen was essentially right in regarding the periosteum as a limiting membrane. I have hitherto denied this. I was wrong.

As to the so-called internal callus, my specimens show no evidence of any effective rôle played by it in the process of union. Sometimes scattered trabeculae appeared within the marrow canal, and sometimes there was no bone formation there at all; but even when present, the trabeculae were apparently not serving any useful purpose. It seems, then, that while this internal callus is the chief means whereby nature repairs the damage done by boring a hole in the cortex, when there is

5. Ely, L. W.: Experimental Resection of the Dog's Knee Joint, Ann. Surg. 70:586 (Nov.) 1919. Ely, L. W., and Cowan, J. F.: Experimental Resection of the Dog's Knee Joint. Bone and Joint Studies, I, Stanford University, Published by Stanford University, 1916. 
an actual solution of continuity between the fragments of a fracture, the internal callus is a negligible factor. This is in line with the impression which one gets from studying roentgenograms of fractures clinically. These show that the whole process of repair takes place outside the cortex.

In almost all our specimens, marked displacement of the fragments had taken place, and they were separated by a distinct interval. This interval, bounded on two sides by cortex, and on two sides by periosteum, became filled with cartilage, fibrous tissue and fibrocartilage. Union of the two fragments took place by ossification of this mass of cartilage and fibrocartilage very much as ossification takes place in an epiphysis, by the penetration of blood vessels. The ossification advances from the cortex, and is especially marked in the angle made where the periosteum leaves the cortex. In no case was there any evidence of bone formation along the periosteum where it stretched across between the fragments. In other words :

2. Ossification of the soft callus takes place from the extcrnal aspect of the cortcx. This also agrees with roentgen-ray evidence. What has been assumed from roentgen-ray evidence, however, to be a bony bridge built by the activity of the periosteum, is really the result of bone formation proceeding from the cortex. The few experiments which were allowed to run for a considerable time indicated that after bony union was complete, the apposed and overlapping cortices were being torn down, and that a rearrangement of the bone architecture was going forward. Presumably, a new cortex would be formed in the bony callus, and a central medullary canal would be established within it.

In the cases of nonunion, the fundamentals of the formation of the soft callus were the same as in the other cases, except that the production of fibrous tissue was possibly more abundant. New bone developing from cartilage appeared on the outside of the cortex in these cases also. The chief distinguishing mark in these two series was the formation of rifts in the fibrous tissue of the soft callus, and when the soft callus was transformed partially or completely into cartilage and bone, the large rift or series of rifts constituted a regular joint, lined by cartilage or by fibrocartilage, sometimes in places showing a distinct villous formation, like that of a synovial membrane.

This formation of a new joint is the rule in the series of experiments in which circular division of the periosteum was carried out. Only one case of the series showed bony union. The series in which the periosteum was slit does not show this almost uniform tendency. The cases are too few for accurate judgment, but, roughly, bony union is about as frequent in the uninfected cases which have run a sufficient time as is new joint formation. In other words: 
1. When the periosteum is intact, bony union is to be expected.

2. When the periosteum is completely divided, bony union is not to be expected.

3. When the periosteum is slit, bony union may or may not take place.

\section{CONCLUSION}

After an ordinary fracture, hemorrhage takes place from the marrow canal under the periosteum. The periosteum is stripped up from the cortex by this hemorrhage and by the fracture itself. Then come the deposition of fibrin, the formation of granulation tissue and the formation of cartilage and fibrocartilage in the space beneath the stripped-up periosteum. Probably the function of the periosteum is only important in the early stages, up to the formation of the cartilaginous callus. The periosteum probably serves to keep the hemorrhage from escaping and the granulation tissue undisturbed. It has no bone-forming function, and bone is not built out of it. The subsequent ossification of the cartilaginous callus is carried out almost entirely, if not exclusively, from the external aspect of the cortex. The internal callus plays no effective part in the union. It is rudimentary when it is present. 